\title{
Probabilistic fire demand model for steel pipe-racks exposed to localised fires
}

\author{
Jérôme Randaxhe ${ }^{1,2}$, Nicoleta Popa ${ }^{2}$, Nicola Tondini ${ }^{1}$ \\ ${ }^{1}$ Department of Civil, Environmental and Mechanical Engineering, University of Trento, Italy \\ nicola.tondini@unitn.it \\ ${ }^{2}$ Global R\&D Center of ArcelorMittal, Esch-sur-Alzette, Luxembourg \\ jerome.randaxhe@arcelormittal.com, nicoleta.popa@arcelormittal.com
}




\section{Abstract}

This paper proposes a new method to build a probabilistic fire demand model (PFDM) to investigate the structural behaviour of a steel pipe-rack located within an industrial installation and exposed to a localised fire. The PFDM will serve to develop fire fragility functions to be used either in a fire risk assessment or in a fully probabilistic structural fire engineering (PSFE) framework. The cloud analysis (CA) was exploited to build a PFDM based on different engineering demand parameters (EDP) - intensity measures (IM) pairs. In particular, the analysis was applied to a prototype steel pipe-rack integrating an industrial plant in Italy. In order to cover a wide range of plausible fire scenarios and to introduce uncertainties in the fire model, 539 fire scenarios were examined by varying the fire diameter, the fire-structure distance and the fuel. The selection of the fire diameters was based on parametric analyses quantifying liquid flow through orifices and pipes. The thermal impact of the pool fires on the structure was analysed using the LOCAFI localised fire model and the thermo-mechanical response of the pipe rack was evaluated by means of finite element analysis. Based on the structural analysis outcomes, it was found that the interstorey drift ratio (ISDR) - average heat flux impinging the structure $\left(\mathrm{HF}_{\text {avg }}\right)$ EDP-IM pair was the most efficient and was also characterised the highest relative sufficiency among the other pairs. Moreover, it has to be noted that for this type of case study, the CA revealed to be a suitable and versatile tool to build a PFDM.

Keywords: probabilistic fire demand model; cloud analysis; pool fires; LOCAFI model; fire fragility functions; steel pipe-rack structure

\begin{tabular}{|c|c|c|c|c|c|}
\hline \multicolumn{6}{|c|}{ Nomenclature } \\
\hline $\mathrm{L}_{\mathrm{Fl}}$ & length of the conical flames & [m] & $A_{h}$ & cross-sectional area of the hole & {$\left[\mathrm{m}^{2}\right]$} \\
\hline $\mathrm{Q}$ & rate of heat release (RHR) & {$[\mathrm{W}]$} & $P$ & total pressure at the opening & {$\left[\mathrm{N} / \mathrm{m}^{2}\right]$} \\
\hline $\mathrm{D}$ & fire diameter & {$[\mathrm{m}]$} & $P_{h}$ & hydraulic liquid pressure & {$\left[\mathrm{N} / \mathrm{m}^{2}\right]$} \\
\hline$T(z)$ & temperature along the flame axis & [m] & $\mathrm{PaL}_{\mathrm{at}}$ & external pressure above liquid & {$\left[\mathrm{N} / \mathrm{m}^{2}\right]$} \\
\hline $\mathrm{Q}_{c}$ & convective part of the RHR & {$[\mathrm{W}]$} & $\mathrm{Pa}_{\mathrm{a}}$ & atmospheric pressure & {$\left[\mathrm{N} / \mathrm{m}^{2}\right]$} \\
\hline $\mathrm{z}$ & height considered along the flame axis & [m] & $\rho_{\mathrm{L}}$ & liquid density & {$\left[\mathrm{kg} / \mathrm{m}^{3}\right]$} \\
\hline $\mathrm{z}_{0}$ & virtual origin of the fire source & {$[\mathrm{m}]$} & $h_{L}$ & relative liquid height & [m] \\
\hline$\dot{\mathrm{m}}_{\mathrm{b}}$ & mass burning rate of a fuel & {$\left[\mathrm{kg} / \mathrm{m}^{2} \mathrm{~s}\right]$} & $\mathrm{g}$ & gravitational acceleration & {$\left[\mathrm{m} / \mathrm{s}^{2}\right]$} \\
\hline$\Delta \mathrm{H}_{\mathrm{c}}$ & heat of combustion of a fuel & {$[\mathrm{kJ} / \mathrm{kg}]$} & $\mathrm{H}$ & tank height & {$[\mathrm{m}]$} \\
\hline$\dot{\mathrm{m}}_{\infty}$ & limiting burning rate of a fuel & {$\left[\mathrm{kg} / \mathrm{m}^{2} \mathrm{~s}\right]$} & $\phi$ & tank filling degree & [\%] \\
\hline $\mathrm{k} \beta$ & empirical constant of a fuel & {$\left[\mathrm{m}^{-1}\right]$} & $\mathrm{h}$ & height of the leakage source & [m] \\
\hline \multirow[t]{2}{*}{$q_{A \rightarrow B}$} & radiative heat flux emitted by a surface $A$ & {$\left[\mathrm{~W} / \mathrm{m}^{2}\right]$} & $\Delta \mathrm{P}$ & pressure drop in a pipe & {$\left[\mathrm{N} / \mathrm{m}^{2}\right]$} \\
\hline & and received by a surface $B$ & & $f_{D}$ & Darcy friction factor & {$[-]$} \\
\hline$\phi_{A \rightarrow B}$ & configuration factor between surfaces $A$ and $B$ & {$[-]$} & $\mathrm{u}_{\mathrm{L}}$ & liquid flow velocity & {$[\mathrm{m} / \mathrm{s}]$} \\
\hline$\varepsilon_{\mathrm{A}}$ & emissivity of a surface $A$ & {$[-]$} & $I_{p}$ & pipe length & {$[\mathrm{m}]$} \\
\hline$\theta_{\mathrm{A}}$ & temperature of a surface $A$ & {$[\mathrm{~K}]$} & $d_{p}$ & pipe diameter & {$[\mathrm{m}]$} \\
\hline$\sigma$ & Stephan Boltzmann constant & {$\left[\mathrm{W} / \mathrm{m}^{2} \mathrm{~K}^{4}\right]$} & $\varepsilon$ & pipe wall roughness & [m] \\
\hline $\mathrm{q}_{\mathrm{s}}$ & mass flow rate & {$[\mathrm{kg} / \mathrm{s}]$} & $\eta_{\mathrm{L}}$ & liquid dynamic viscosity & {$\left[\mathrm{N} . \mathrm{s} / \mathrm{m}^{2}\right]$} \\
\hline$C_{d}$ & discharge coefficient & {$[-]$} & $\operatorname{Re}$ & Reynold's number & {$[-]$} \\
\hline
\end{tabular}




\section{Introduction}

In industrial and petrochemical plants, piping systems are used to transport flammable material, liquid or gas fuel, on long distances. They are usually supported by pipe-rack steel structures, passing between other industrial components, e.g. tanks, distillation tower, etc. These structures usually unprotected due to their important length, are components among the most exposed to natural hazards, such as earthquakes, hurricane or tsunamis. It appears in plants that under certain conditions, these events can trigger severe structural damages, leading a pipe or a tank to lose its containment. Furthermore, petrochemical plants are locations where a releasing flammable material is more likely to ignite than anywhere else due to activities and operations taking place in industrial environments. Even if the probability of occurrence is low, the consideration of such scenarios cannot be ignored, given their catastrophic consequences. Numerous studies have recently highlighted the exposure of petrochemical plants piping systems to natural hazards generating technological issues, also named NaTech events. Among the wide research work which has been undertaken, Zheng and Chen [1] investigated storage tank fire accidents due to maintenance and management problems. Uehara [2] focused on fire safety assessments in petrochemical plants by prescribing a method to evaluate the potential dangers of fire accident with facilities storing flammable material. Chan and Lin [3] reviewed 242 accidents involving storage tanks and analysed their causes to identify that $85 \%$ of accidents impacting petrochemical facilities are due to fires and explosions. Pantousa [4] investigated the behaviour of steel storage tanks when exposed to the thermal radiation from surrounding burning tanks. Yet-pole I et al. [5] simulated fires and explosions within a Naphtha-cracking plant and evaluated the resulting risks through a quantitative risk analysis. Considering other NaTech events than fire, Padgett and Bernier [6] developed a fragility model for above storage tank exposed to multi-hazard storm conditions. Phan et al. [7] analysed the seismic vulnerability of an elevated steel storage tank supported by reinforced concrete columns, by developing a probabilistic demand model. Numerous seismic analyses were performed on petrochemical piping systems and their support structure by Paolacci et al. [8]-[12]. They namely considered an existing steel pipe rack as case study and delivered performance-based seismic analyses. Nakashima et al. [13] presented the time evolution of earthquake mitigation and recovery and proposed additional research topics which remain to be investigated based on 2011 Tohoku earthquake. Campedel et al. [14] developed a procedure to assess industrial risk due to NaTech events, with the use of a quantitative risk analysis. European standards currently prescribe two approaches to design a structure against fire hazards, prescriptive- and performance-based approaches [15]. Prescriptive approaches use conservative fire curves (ISO834 curve, hydrocarbon curve, ...) giving temperature evolutions with time, to be applied on the frontiers of the structural members considered. Prescriptive fire curves do not represent the real fire behaviour, whilst performance-based approaches exploit natural fire curves that are built considering the fire characteristics and the environment, in which the structure is located. Thus, the evaluation of the thermal actions impacting the structure is based on the fire load, the supply of oxygen, and the boundary conditions in case of compartment fires. Performance-based approaches usually yield less severe thermal actions, that implies cost saving in fire protections, but it requires expertise.

Specifically, this work adopts a performance-based approach to investigate the thermo-mechanical response of a steel pipe-rack subjected to a number of meaningful fire scenarios of pool fire located beside it with the aim to build a probabilistic fire demand model from which deriving fire fragility functions. For that purpose, a pool fire model must be selected, allowing the simulation of a burning tank and a localised 
fire resulting from leakage and loss of containment. It is worth pointing out that the governing heat transfer mechanism of a localised fire impacting a structure that is not ingulfed into the fire, is radiation. Thus, the definition of localised fire models able to predict thermal radiation is paramount. In this respect, several models were developed to study the thermal radiation from hydrocarbon pool fires based on experimental observations [16-24]. In more detail, Shokri and Beyler [16][17] developed a method to predict the radiative heat flux emitted from large pool fires and received by a target outside the flame, by exploiting the Heskestad correlations [18] to characterise the flame length. Rew and Hulbert [19] defined a mathematical semi-empirical model to quantify the thermal radiation from hydrocarbon pool fires. This model gathers the research works achieved by Babrauskas [20], Thomas [21], and Mudan [22] for the definition of the mass burning rate, the flame length, and the surface emissive power from the flame, respectively. The Shokri and Beyler model, the Mudan model and the point source models are compared, and significant differences are discussed by Ufuah and Bailey [23], li-bin et al. [24] and Beyler [17]. More recently, in the framework of a European research project, the LOCAFI analytical model was developed to compute the radiative heat flux received by vertical structural elements from a pool fire [25]-[30]. This method aims to address situations where the fire hazard can be described by localised fires due to compartment geometry and/or fire load (e.g. burning car in a car park, fire in a large airport hall, ...). It quantifies the thermal impact of pool fires on surrounding columns. The definition of the flame shape, assumed to be conical is based on the Heskestad flame length correlation [18][26].

It is clear that the investigation of the causes of ignition of a pool fire in an industrial or petrochemical plant represents a key factor to highlight that the selected scenarios, though with low probability, are plausible. In this respect, Gottuk and White [31] provided methods to evaluate the occurrence of liquid fuel leakage and the consequent growth and the size of the potential resulting fire. The 'Yellow Book', developed by the committee for the prevention of disasters by hazardous materials [32], provides a method to quantify the mass flow rate resulting from a fuel leakage through a hole in a tank wall or in a pipe considering the pressure loss. Scenarios with multiple pool fires are not addressed in this work, but they could be part of future works. Vilchez et al. [33] studied the probabilities of observing a leakage leading to pool fire and Moosemiller [34] developed algorithms to predict ignition probabilities.

Fragility functions are convenient tools when decisions are to be taken in structural design considering uncertainties. More specifically, for a given structure exposed to fire, a fragility function computes the probability that a structure reaches a predefined damage state (e.g. beam deflection level, interstorey drift ratio, critical temperature, ...) depending on an intensity measure characterising the fire (e.g. fire load, fire geometry, ...). There are few research works addressing the development of fragility functions in fire field. In particular, Gernay et al. [35] [36] proposed a methodology to define fire fragility functions for a steel building exposed to compartment fires considering different fire loads. If this approach is relevant for buildings intended for offices and dwellings, it cannot be applied for a steel pipe-rack exposed to a localised fire. Lange et al. [37] and Shrivastava et al. [38] modified and adapted to fire engineering the widely used Performance-Based Earthquake Engineering (PBEE) approach from the Pacific Earthquake engineering research center (PEER) probabilistic framework [39]. The use of fragility functions, considering efficient intensity measures to characterise the fire severity, allows the mitigation of fire risks when petrochemical plants are designed. In that sense, this work aims to develop a probabilistic fire demand model. Indeed, there are three popular methods to compute probabilistic fire demand models: cloud analysis, incremental dynamic analysis, and multiple stripe analysis. Their use namely depends on 
the form of the data collected. Mackie and Stojadinovic [40] compared these three methods and discussed their merits and drawbacks relatively to the seismic domain. Shome et al. [41] and Cornell et al. [42] established the basis of the cloud analysis with seismic application. That method was namely adopted by Mackie and Stojadinovic [43], and Tondini and Stojadinovic [44] to develop a probabilistic demand model in the seismic field for bridge design, and for curved reinforced concrete bridges, respectively. Baker [45] studied the merits of multiple stripe analysis and developed a methodology to fit probabilistic results with fragility functions using maximum likelihood estimation. The efficiency and sufficiency of IM was investigated in earthquake engineering by Luco and Cornell [46] and in fire engineering by Shrivastava et al. [38]. Jalayer et al. [47] proposed an alternative manner to evaluate the sufficiency of IM by computing the relative sufficiency between two potential IMs. However, there is a lack of work related to the study of probabilistic fire demand models relative to the structural fire behaviour of supporting structures in industrial plants.

On these premises, the European XP-RESILIENCE project [48] was funded, with the objective to develop tools enhancing the resilience of petrochemical plants against NaTech events. These tools encompass the development of guidelines, methodologies and advanced modelling and the development of structural protections namely based on metamaterials structures. Among these objectives, there is the investigation of fire hazards in petrochemical plants and, more specifically, there is the analysis of the impact that a pool fire can have on surrounding pipe-rack structures due to heat radiation. In industrial plants, pool fires can result from a flammable material leakage or from a burning tank. To investigate this NaTech event in a proper way, this paper aims to develop a probabilistic fire demand model prescribing a methodology to derive fire fragility functions for steel pipe-rack exposed to a localised fire. Hence, the paper is organised as follows: Section 0 defines the prototype steel pipe-rack used as case study for the development of the probabilistic fire demand model. Section 3 briefly introduces the LOCAFI model, investigates the ignition of a pool fire resulting from fuel leakage and defines the range of fire scenarios considered in this study. Section 4 introduces the probabilistic approach by describing the method considered to derive fragility curves, the results of the thermo-mechanical analysis and describes the fire fragility function derivation. Finally, conclusive remarks and future perspective are drawn Section 5.

\section{Case study: Prototype steel pipe-rack}

\subsection{Description of the structure}

The reference steel pipe-rack was taken from an existing petrochemical plant located in Italy. As depicted in Figure 1, the structure is composed of several steel frames with rigid beam-to column joints and pinned column-base joints in the transversal direction, whose distance from each other is $6 \mathrm{~m}$; whereas, in the longitudinal direction, the structure is braced, with modules composed of seven bays and only one endowed with bracings. The structural members are commercial HEA and HEB steel profiles. Horizontal braces are used to limit relative displacements between the frames and the pipe supports. The structure presents some characteristics specific to the plant where it was installed, as for example the different column heights to fit the site topography and the bridge portion. The seismic behaviour of this pipe rack and its piping system was deeply studied by Paolacci et al. and Bursi et al. in [8-12].

For the interest of the analyses addressed in this paper, the reference pipe-rack geometry was modified with the following assumptions. Firstly, only the supporting steel pipe-rack was considered while the 
structural contribution of the piping system was neglected. Indeed, the pipes could offer a contribution in terms of stiffness of their connections with the pipe-rack. However, most of the time, their connections are flexible to mitigate thermal and pressure effects or dissipative to introduce more damping. Therefore, it is a safe approach to merely neglect the piping system stiffness. Secondly, since a pipe-rack is, by definition, a structure intended for carrying pipes on kilometres and usually composed of modular and repeated portions, it was decided to focus the analyses on a limited and regular part. On these premises, the prototype steel pipe-rack considered for this work is defined in Figure 2. The steel grade is an S275. The columns are HEA 340, the longitudinal beams are HEA 200 and the transversal beams are HEA- and HEB 300 steel profiles, respectively. The self-weight of the pipe and their content is evaluated to $75 \mathrm{kN} / \mathrm{m}$. This load corresponds to a pipe arrangement as depicted in Figure 3, considering 22" DN550 SCH140 pipes presenting a diameter of $559 \mathrm{~mm}$ with a wall thickness of $47 \mathrm{~mm}$, and filled with a fuel presenting a density of $780 \mathrm{~kg} / \mathrm{m}^{3}$. The horizontal load is equal to $2 \mathrm{kN} / \mathrm{m}$, considering the friction of the pipes, that are uniformly distributed on the transversal beams. Vertical contingency operating point loads of $15 \mathrm{kN}$ and horizontal contingency friction point loads of $7.5 \mathrm{kN}$ are applied at mid-span of the longitudinal beams. Wind loads acting on the structure are not considered during the fire. The loads applied on the pipe-rack are detailed in Figure 4. It has to be noted that this load combination represents about $50 \%$ of the structure vertical bearing capacity.

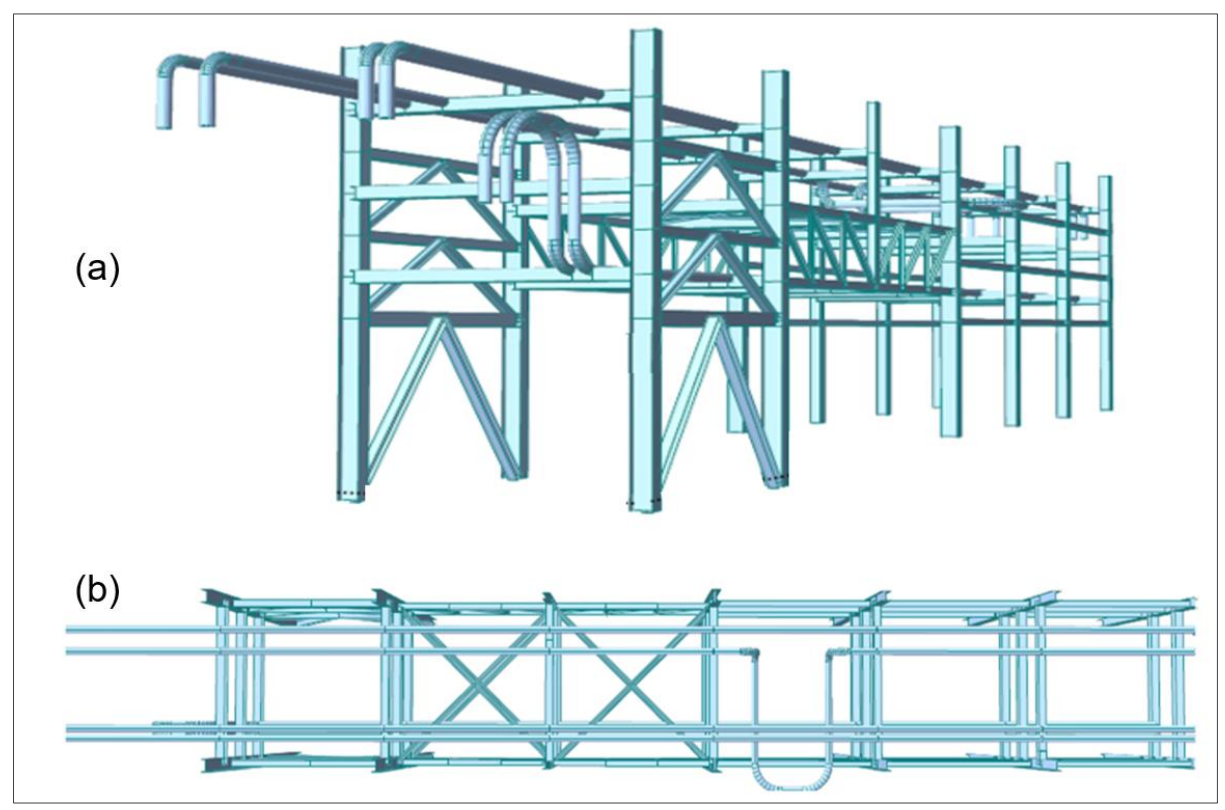

Figure 1 - Existing reference steel pipe-rack: (a) 3D view; (b) Top view 

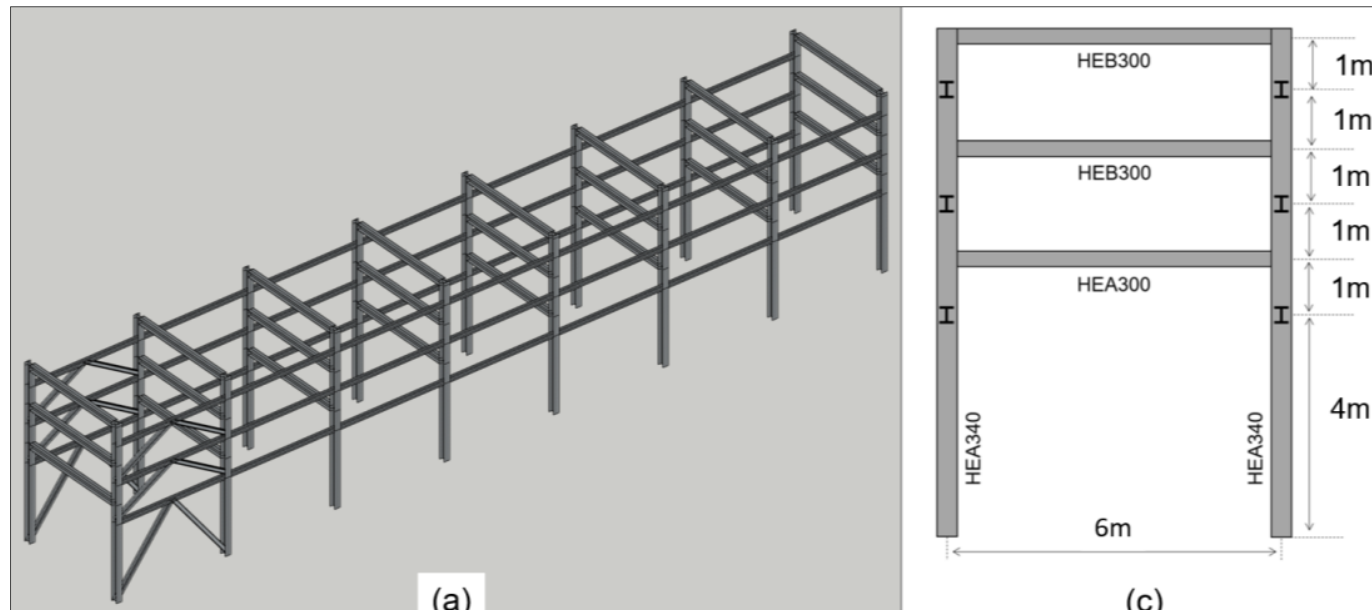

(a)

(c)

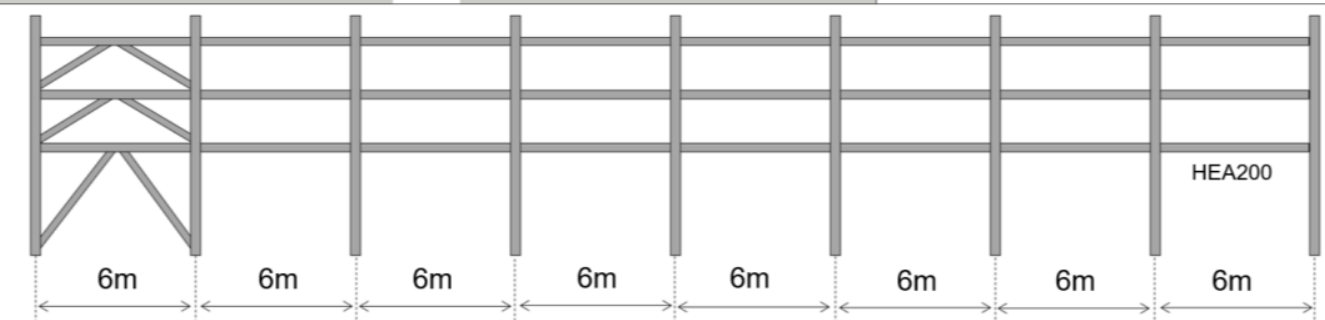

(b)

Figure 2 - Prototype steel pipe-rack: (a) 3D view; (b) Longitudinal view; (c) Transversal view

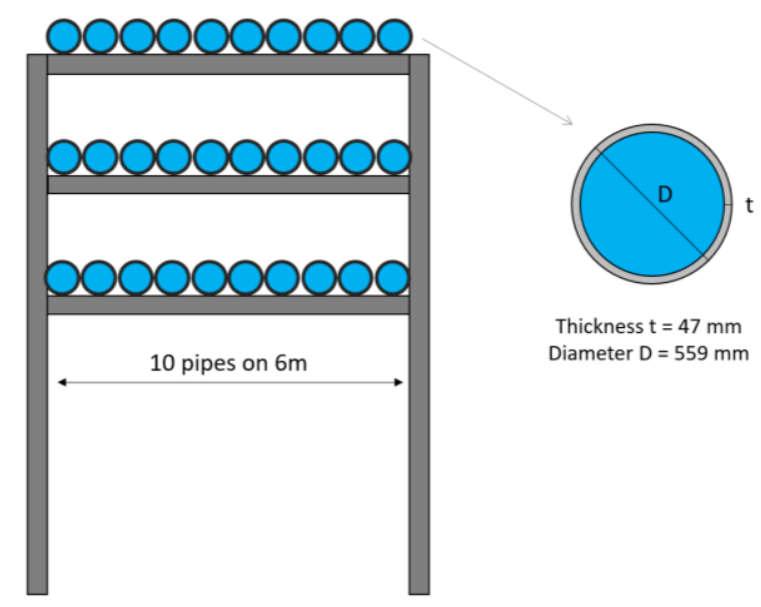

Figure 3 - 22" DN550 SCH140 pipe arrangement 


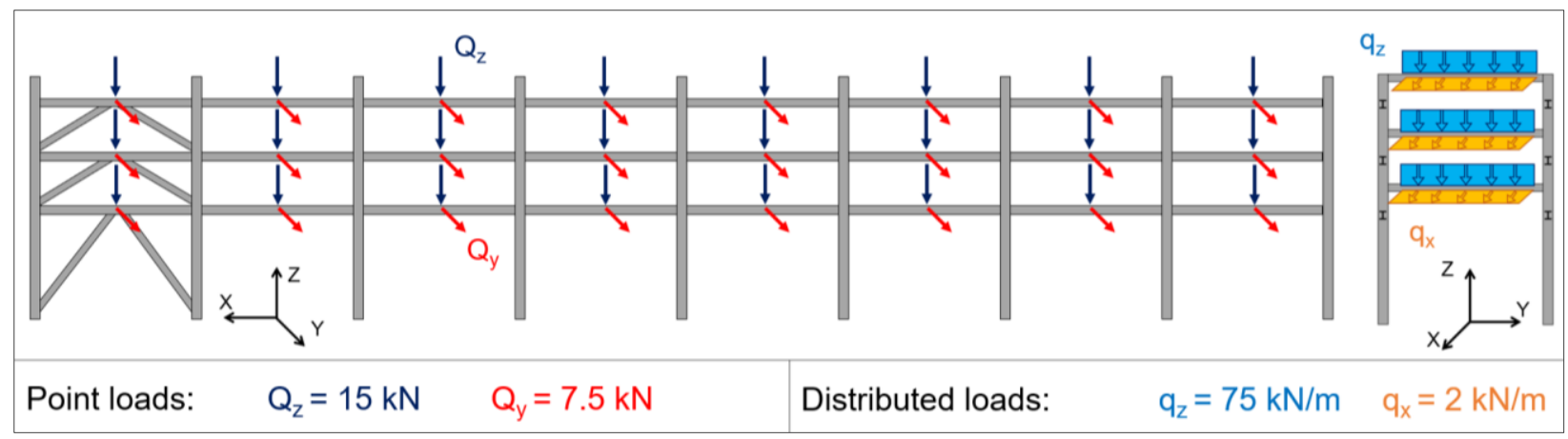

Figure 4 - Loads applied on prototype pipe-rack

\subsection{Numerical model}

The pipe rack described in Section 2.1 was modelled with the thermo-mechanical non-linear finite element software SAFIR [49]. This software includes the LOCAFI model, as described in Section 3.1. The structural response of the pipe-rack exposed to a localised fire was investigated by means of a 3D model that exploited 3D Bernoulli fibre-based beam elements. Thus, at each integration point 2D thermal analyses were performed with heat flux boundary conditions obtained from the application of the LOCAFI model. The entire structure was discretized with beam elements having length of $50 \mathrm{~cm}$ and containing two points of integration each. That represents a total of 936 beam elements to model the prototype pipe-rack. The properties of steel at elevated temperature were taken as the ones provided in EN 19931-2 [50]. The boundaries conditions assigned to the structural model comply with the assumptions formulated in Section 2.1. As described in Figure 5, the columns HEA340 are continuous and pinned at their base in both principal directions. The transversal beams HEA- and HEB300 are both end fixed to the columns, while the longitudinal beams, HEA200 are pinned to the columns. At both longitudinal ends of the pipe-rack, horizontal restraints were applied to allow for the bracing system that was not modelled to limit the computational burden. This modelling was justified by the fact that based on the fire scenarios described in Section 3.3, the heating of the bracing system was not enough to significantly change its degree of restraint. Moreover, the major thermal impact and the consequent structural failure occurred in the transverse direction. It may be noted that longitudinal thermal expansion joints were not considered in the structural module under study.

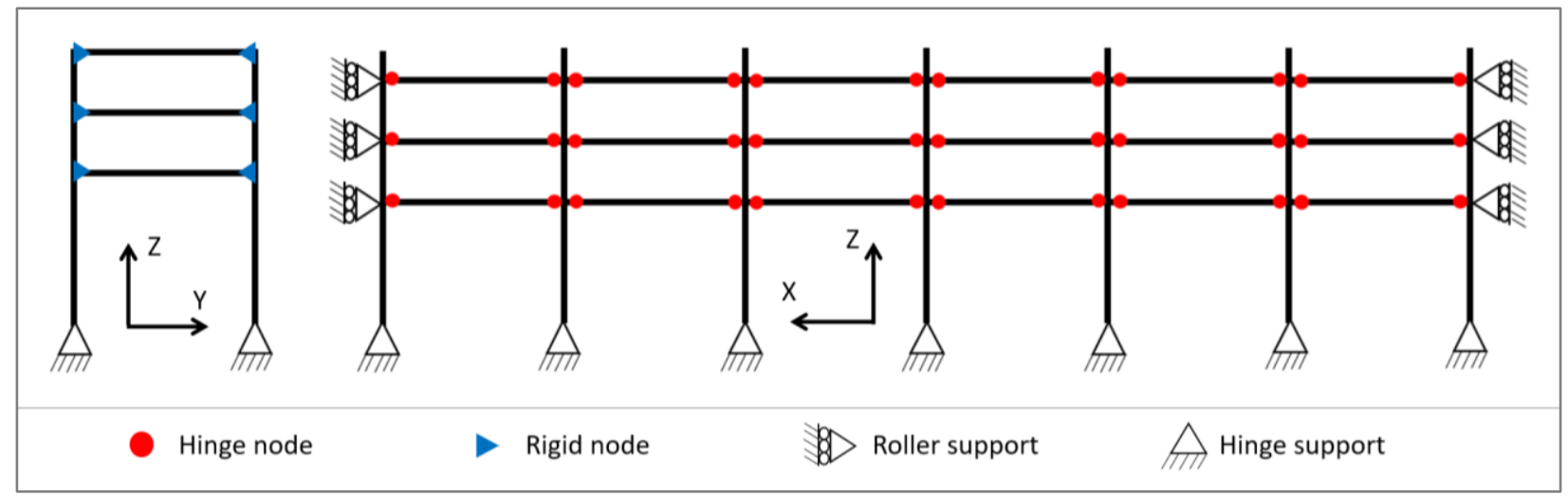

Figure 5 - Boundary conditions of the 3D FE model of the prototype steel pipe-rack 


\section{Localised fire scenarios}

\subsection{LOCAFI model}

Pool fires are localised fires resulting from a liquid or solid fuel burning on a limited surface. Several models are available in literature to study pool fires and they can be classified among field/computational fluid dynamics (CFD) models and empirical/analytical models. Tondini et al. [26] showed how the analytical LOCAFI model compared with CFD models to predict the radiant heat flux emitted from pool fires and how it fared against experimental measurements. Indeed, CFD models can provide an accurate modelling of a localised fire by solving Navier-Stokes differential equations of fluid flow. However, their use requires high computational capacity and specific expertise. On the other hand, empirical/analytical models allow the study of the impact of pool fires in a simplified way with stricter application fields. They generally provide description of the flame geometry and quantify the emitted radiative heat flux from the fire to a target. A distinction can be made between point source models [51] and solid flame models [19]. In point source models the radiative heat flux emitted by the fire and received by an external target can be simplified as one single heat flux emitted from a unique point located at the centre of the flame. This model is convenient to implement because of its simple geometry and its low calculation demand. On the other hand, solid flame models adopt a specific shape for the flame geometry, that may be a cylinder, an ellipse or a cone [16],[26]. These models consider that the radiative heat fluxes are emitted from the surfaces of the solid representing the fire and that the radiative heat flux received by an external element is the sum of the radiative heat fluxes emitted from each surface based on the computation of configuration factor, which may be done analytically and/or numerically depending on the flame shape assumption. Solid flame models are more complex than point source models in terms of calculations, but they generally provide a better representation of the heat flux associated with a larger field of application. In the framework of this research, a solid flame model is adopted with the use of the LOCAFI model developed within the European LOCAFI Project [25]. This model was developed and calibrated based on experimental tests and numerical analyses performed with a CFD model [26]. A brief description is summarized herein.

The LOCAFI model represents the localised fire with a conical shape, as depicted in Figure 6. It means that the fuel is distributed in such a way that an equivalent circular representation of its distribution is still a reasonable assumption, i.e. when the ratio of the two sides of a hypothetical rectangular distribution is not greater than two. It has to be noted that LOCAFI model neglects wind effects, as it was done in this work. The fire model relies on the existing localised fire correlations provided in Annex C of EN1991-2 [15]. Thus, the length of the flame is defined in Eq. (1) as a function of the fire diameter $D$ and the rate of heat release $Q$. 


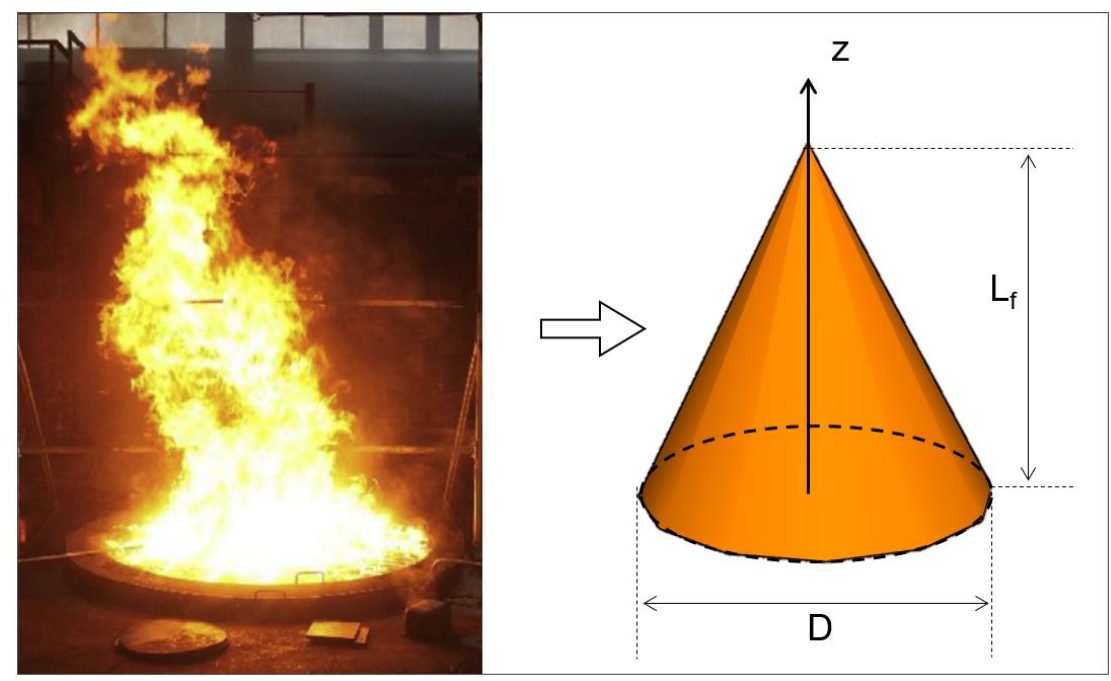

Figure 6 - Solid flame modelled with conical shape in the LOCAFI model

$$
L_{f}=0.0148 Q^{0.4}-1.02 D \quad[\mathrm{~m}]
$$

When a localised fire takes place in open air as is the case in the present research, the temperature along the vertical flame axis can be expressed with Eq. (2) as a function of the height $z$, the convective part of the RHR $Q_{c}$ and the virtual origin of the fire source $z_{0}$, defined in Eq. (3) and Eq. (4).

$$
\mathrm{T}(\mathrm{z})=20+0.25 \mathrm{Q}_{\mathrm{c}}^{2 / 3}\left(\mathrm{z}-\mathrm{z}_{0}\right)^{-5 / 3} \leq 900 \quad\left[{ }^{\circ} \mathrm{C}\right]
$$

where

$$
\begin{array}{ll}
\mathrm{Q}_{\mathrm{c}}=0.8 \mathrm{Q} & {[\mathrm{W}]} \\
\mathrm{z}_{0}=0.00524 \mathrm{Q}^{0.4}-1.02 \mathrm{D} & {[\mathrm{m}]}
\end{array}
$$

With these correlations, a conical fire can be defined for any localised fire with the fire diameter $D$ and the type of fuel. The RHR, as defined in Eq. (5), is function of fire diameter D and two fuel parameters: the mass burning rate $\dot{\mathrm{m}}_{\mathrm{b}}\left(\mathrm{kg} / \mathrm{m}^{2} \mathrm{~s}\right)$ and the heat of combustion $\Delta \mathrm{H}_{\mathrm{c}}(\mathrm{kJ} / \mathrm{kg})$. The mass burning rate $\dot{\mathrm{m}}_{\mathrm{b}}$ of fuel per unit of surface area for liquids was defined by Zabetakis and Burgess [52] and expressed in Eq. (6). Limiting mass burning rate $\dot{m}_{\infty}\left(\mathrm{kg} / \mathrm{m}^{2} \mathrm{~s}\right)$ and the product between the extinction coefficient $\mathrm{k}\left(\mathrm{m}^{-1}\right)$ and a 'mean beam length corrector' $\beta$, defining an empirical constant, are properties depending on the fuel. Table 1 lists the properties of the fuels employed in this work, which are hydrocarbon fuels that can be stored in tanks and introduce variability in the fire source. It has to be noted that for pentane the mass burning rate was taken as the limiting mass burning rate.

$$
\mathrm{Q}=\dot{\mathrm{m}}_{\mathrm{b}} \Delta \mathrm{H}_{\mathrm{c}}\left(\frac{\mathrm{D}^{2} \pi}{4}\right)
$$

$[\mathrm{kW}]$

With

$$
\dot{\mathrm{m}}_{\mathrm{b}}=\dot{\mathrm{m}}_{\infty}\left(1-\mathrm{e}^{-\mathrm{k} \beta \mathrm{D}}\right) \quad\left[\mathrm{kg} / \mathrm{m}^{2} \mathrm{~s}\right]
$$

Once a localised fire is defined with a conical shape and a temperature evolution along the flame axis, incident radiative heat fluxes can be computed for any external element considered. Eq. (7) defines the incident radiative heat flux $\dot{\mathrm{q}}_{\mathrm{A} \rightarrow \mathrm{B}}$ emitted by a surface $A$ and received by a surface $B$. 


$$
\dot{\mathrm{q}}_{\mathrm{A} \rightarrow \mathrm{B}}=\phi_{\mathrm{A} \rightarrow \mathrm{B}} \varepsilon_{\mathrm{A}} \sigma\left(\theta_{\mathrm{A}}+273.15\right)^{4} \quad\left[\mathrm{~W} / \mathrm{m}^{2}\right]
$$

Table 1 - Fuels properties [51]

\begin{tabular}{cccccc}
\hline Fuel & $\begin{array}{c}\text { Limiting mass } \\
\text { burning rate } \\
\mathrm{m}_{\infty}\left[\mathrm{kg} / \mathrm{m}^{2} \mathrm{~s}\right]\end{array}$ & $\begin{array}{c}\text { Empirical } \\
\text { constant }\end{array}$ & $\begin{array}{c}\text { Heat of } \\
\text { combustion }\end{array}$ & Density & Viscosity \\
\hline Acetone & 0.038 & 2.24 & 25800 & 784 & $3.16 \mathrm{E}-04$ \\
Fuel Oil & 0.034 & 1.67 & 39700 & 960 & $3.10 \mathrm{E}-01$ \\
Gasoline & 0.055 & 1.48 & 43700 & 750 & $6.00 \mathrm{E}-04$ \\
Kerosene & 0.063 & 1.27 & 43000 & 780 & $1.64 \mathrm{E}-03$ \\
Benzene & 0.085 & 2.70 & 40100 & 879 & $6.49 \mathrm{E}-04$ \\
Heptane & 0.081 & 1.39 & 44600 & 684 & $3.76 \mathrm{E}-04$ \\
Pentane & 0.095 & - & 48800 & 626 & $2.14 \mathrm{E}-04$ \\
\hline
\end{tabular}

In this research context, as depicted in Figure 7a, the surface $A$ is an element discretising the conical fire and the surface $B$ is an element discretising the structural steel members. The emissivity of the flame $\varepsilon_{A}$, or $\varepsilon_{f}$, is conservatively taken equal to 1 . Indeed, given the same diameter, this assumption may be truer for some fuels than for others as listed in Table 1, but an accurate emissivity estimate is not straightforward and it was then decided to assume 1 because the derived fragility functions may be used for design purposes. The configuration factor can be determined analytically, if available, otherwise through numerical integration. The configuration factor is calculated considering sizes and orientations of surfaces $A$ and $B$ and the distance separating them. This calculation complexity is function of the discretization level adopted for the fire and for the structure. Two models are available to compute the radiative heat fluxes impacting a structural element; the analytical model [26] and the numerical model [49]. In this work, the model implemented in SAFIR is based on numerical integration of the configuration factor. It discretizes the surfaces of the fire and the member with small elements, as shown in Figure 7b. The temperature of each slice is calculated with Eq. (2), by considering its average height. Steel members are represented with their actual cross-section and shadows effects are considered. As explained in Section 2.2, the structural elements are modelled with beam elements with two points of integration each. At each integration point a 2D thermal analysis is performed with thermal boundary conditions that are representative of the position of the structural element with respect to the localised fire. In fact, for each finite element located on the border of the cross-section, as depicted in Figure 7c, a radiative heat flux is calculated by summing all the radiative heat fluxes emitted by the surfaces discretizing the fire and visible by the element. As an example, Figure 8 depicts the temperature field observed within the crosssection of a HEA340 steel column at a height of $5 \mathrm{~m}$ after $1 \mathrm{~h}$ of exposure to a heptane localised fire characterised by a diameter of $20 \mathrm{~m}$ and located $2 \mathrm{~m}$ away. 

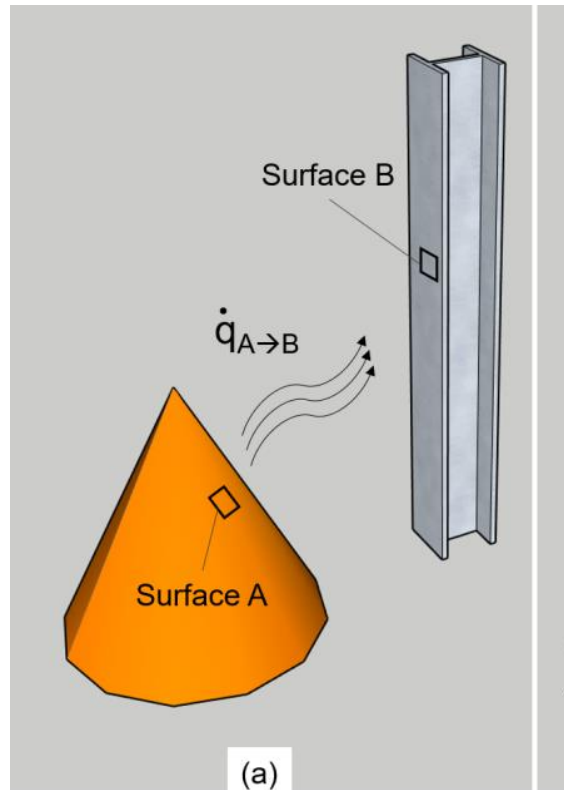

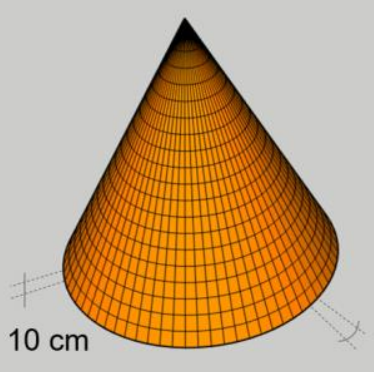

(b)

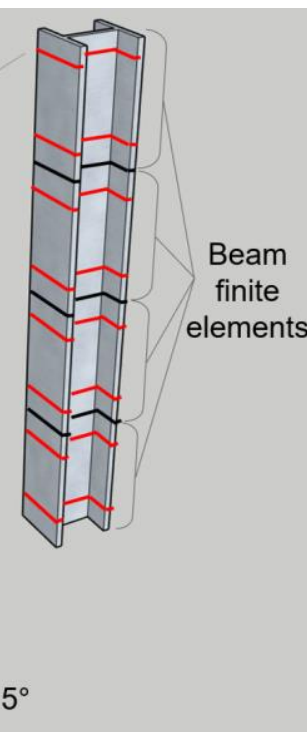

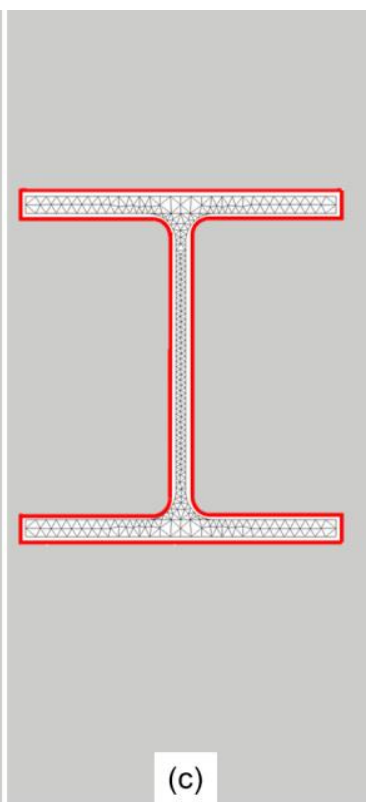

(c)

Figure 7 - (a) Steel column exposed to localised fire; (b) LOCAFI numerical model; (c) Cross-section discretization

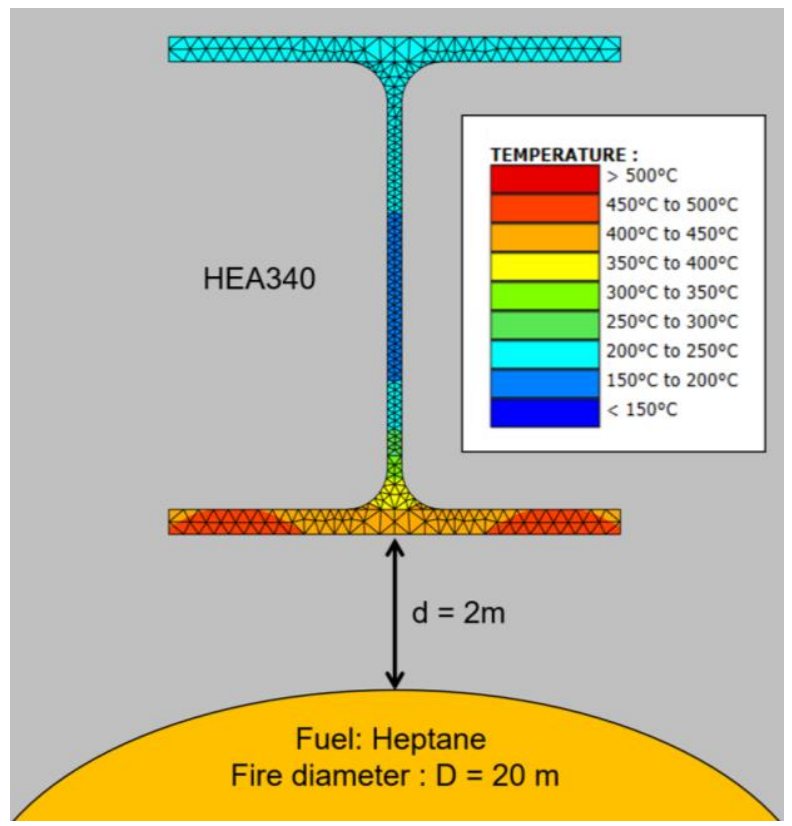

Figure 8 - Temperature field within cross-section observed with numerical model

\subsection{Pool fire ignition and development}

This section describes the potential development of a pool fire from a fuel leakage and highlights the significance of the fire scenarios considered in Section 3.3. In fact, it is possible to quantify the liquid outflow from pipes and tanks resulting from a leakage by determining a mass flow rate $\mathrm{q}_{\mathrm{s}}(\mathrm{kg} / \mathrm{s})[32]$. If the fuel leakage occurs without any ignition, the liquid will simply spill and spread on ground of the plant. However, if the fuel ignites, a pool fire can develop and an equivalent fire diameter can be derived as a function of the mass flow rate and of the mass burning rate of the fuel. Vilchez et al. [33] and Moosemiller 
[34] developed event trees quantifying the probabilities of release and ignition of different fuels. This section assumes that both events may occur and focuses on the quantification of the resulting pool fire. Liquid outflow quantifications for pipes and tanks depends on numerous parameters relative to the tank and pipe geometry, the hole geometry (source of leakage) and the fuel. Two parametric analyses are performed hereafter to cover a maximum of plausible scenarios. The first analysis considers one single tank and computes the fuel leakage resulting from a hole located in the wall of the tank [32]. The second analysis considers a straight pipe connected to a tank and calculates the fuel leakage from a pipe failure. Both situations can result from different causes, such as mechanical impact due to operations on the plant, mechanical damage due to a seismic event or corrosion of the plant equipment due to poor maintenance. For both parametric analyses, the proper application of the models requires the assumptions listed here below [32]:

- $\quad$ The model quantifies non-boiling liquid outflow and neglects liquid vapour pressure.

- The driving force of the leakage is only ensured by the hydraulic pressure.

- The liquid stored in the tank is not pressurized. The model considers the liquid at rest in the tank and neglects any initial liquid velocity.

- The consideration of the hydraulic pressure of a liquid column and the law of conservation of mass are considered accurate enough to model the liquid outflow from a tank or a pipe.

Furthermore, to define the scope of the parametric studies, assumptions and size limitations are specified based on realistic geometries of tanks and pipes. Different parameters, assumed as uniformly distributed, are defined here below and represented in Figure 9.

- The tank diameter varies randomly between

$$
\begin{array}{ll}
3<\mathrm{D}_{\mathrm{T}}<30 & {[\mathrm{~m}]} \\
0.5<\mathrm{H} / \mathrm{D}<1 & {[-]} \\
10<\phi<100 & {[\%]}
\end{array}
$$

- The tank height $\mathrm{H}$ respects a shape factor varying randomly between

- The fuel is randomly selected among 7 different fuels: Ethanol, Acetone, Fuel oil, Gasoline, Kerosene, Heptane and Pentane

- The equivalent diameter of the hole varies randomly between

$$
\begin{array}{ll}
0.01<\mathrm{d}_{\mathrm{H}}<0.1 & {[\mathrm{~m}]} \\
0.03<\mathrm{d}_{\mathrm{p}}<0.3 & {[\mathrm{~m}]} \\
5<\mathrm{I}_{\mathrm{p}}<100 \quad[\mathrm{~m}] \\
0<\mathrm{h}<0.5 \phi \mathrm{H} & {[\mathrm{m}]}
\end{array}
$$

- The pipe diameter varies randomly between

- The height of the leakage source varies randomly between

The leakage source (hole, orifices or tank-pipe connection) is randomly located between the bottom of the tank and the mid-height of the initial liquid height $(\phi H)$. 


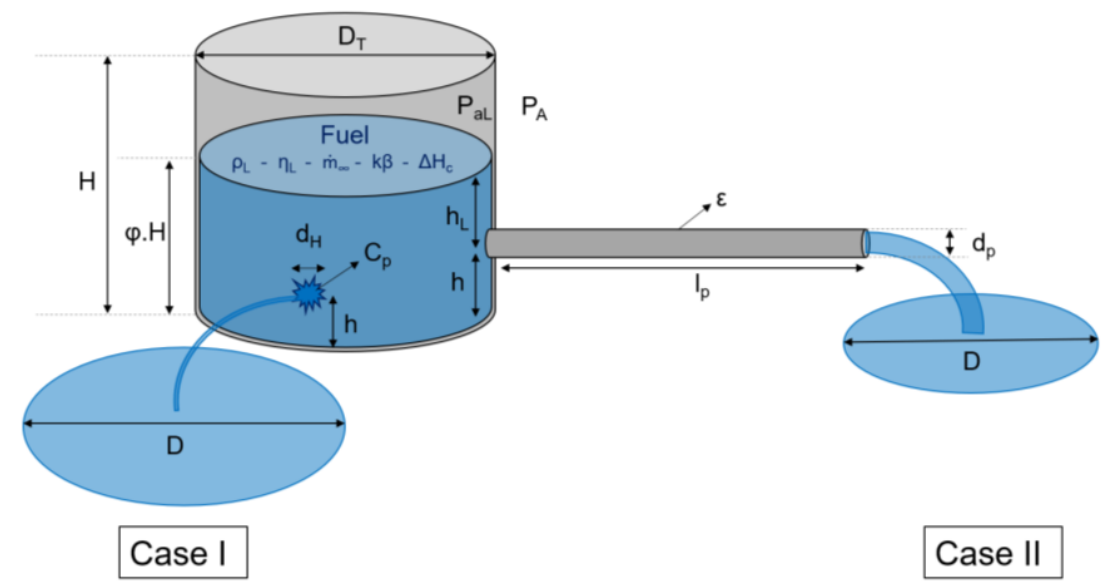

Figure 9 - Liquid outflow through a tank or a pipe: parametrical analyses

\subsubsection{Liquid outflow from tanks}

Liquid flow through an orifice in a tank wall is defined with the use of the Bernoulli equation. By neglecting the initial velocity in the tank, the mass flow rate can be expressed with Eq. (8).

$$
\mathrm{q}_{\mathrm{s}}=\mathrm{C}_{\mathrm{d}} \cdot \mathrm{A}_{\mathrm{h}} \cdot \sqrt{2\left(\mathrm{P}-\mathrm{P}_{\mathrm{a}}\right) \cdot \rho_{\mathrm{L}}} \quad[\mathrm{kg} / \mathrm{s}]
$$

with

$$
\begin{array}{ll}
\mathrm{P}=\mathrm{P}_{\mathrm{h}}+\mathrm{P}_{\mathrm{aL}} & {\left[\mathrm{N} / \mathrm{m}^{2}\right]} \\
\mathrm{P}_{\mathrm{h}}=\mathrm{h}_{\mathrm{L}} \cdot \mathrm{g} \cdot \rho_{\mathrm{L}} & {\left[\mathrm{N} / \mathrm{m}^{2}\right]} \\
\mathrm{h}_{\mathrm{L}}=\phi \cdot \mathrm{H}-\mathrm{h} & {[\mathrm{m}]}
\end{array}
$$

The value of the discharge coefficient $C_{d}$ depends on the shape of the orifice. Table 2 summarizes the coefficients provided by Beek [1975].

Table 2 - Discharge Coefficients Cd

\begin{tabular}{ll}
\hline Type of orifice & $\mathrm{C}_{\mathrm{d}}[-]$ \\
\hline Sharp orifice & 0.62 \\
Straight orifice & 0.82 \\
Rounded orifice & 0.96 \\
Pipe rupture & 1.00 \\
\hline
\end{tabular}

\subsubsection{Liquid outflow from pipes}

Liquid flow through a pipe is defined in a similar way as through holes. However, a drop of pressure in the pipe due to the stationary fluid flow must be taken into consideration and subtracted from the total pressure $\mathrm{P}$ in Eq. (8). This pressure drop $\Delta \mathrm{P}$ can be defined with the Darcy-Weisbach law, expressed in Eq. (12). 


$$
\Delta \mathrm{P}=\frac{\mathrm{f}_{\mathrm{D}} \cdot \rho_{\mathrm{L}} \cdot \mathrm{u}_{\mathrm{L}}^{2} \cdot \mathrm{l}_{\mathrm{p}}}{2 \cdot \mathrm{d}_{\mathrm{p}}} \quad\left[\mathrm{N} / \mathrm{m}^{2}\right]
$$

Darcy friction factor $f_{D}$ is defined by the law of Colebrook-White, as a function of liquid flow velocity $u_{L}$, pipe diameter $d_{p}$, roughness of the pipe wall $\varepsilon$ and liquid viscosity $\eta_{p}$. This factor can be determined by imposing to zero the auxiliary function $F\left(f_{D}\right)$ defined in equation Eq. (13). In this function Re is the Reynold's number defined in equation Eq. (14) and the pipe wall roughness $\varepsilon$ depending the pipe material is given in Table 3 for some practical cases.

$$
\begin{aligned}
& F\left(f_{D}\right)=1 / \sqrt{f_{D}}+2 \cdot \log _{10}\left(\varepsilon /\left(3.715 \cdot d_{p}\right)\right)-2.51 /\left(\operatorname{Re} \cdot \sqrt{f_{D}}\right) \\
& \operatorname{Re}=\rho_{L} \cdot u_{L} \cdot d_{p} / \eta_{L}
\end{aligned}
$$

Table 3 - Pipe wall roughness value

\begin{tabular}{lc}
\hline Pipe Material & Wall roughness $\varepsilon[\mu \mathrm{m}]$ \\
\hline Bronze, lead, glass & 1.50 \\
Commercial steel, wrought-iron & 45.0 \\
Cast iron & 250 \\
\hline
\end{tabular}

It can be observed in Eq. (12), Eq. (13) and Eq. (14), that for a given liquid and a pipe geometry, the pressure drop $\triangle P$ is function of the liquid flow velocity $\mathrm{u}_{\mathrm{L}}$ and the Darcy friction factor $\mathrm{f}_{\mathrm{D}}$ which is function of the liquid flow velocity. Furthermore, this pressure drop must be subtracted from the total pressure in Eq. (8) to determine the mass flow rate $q_{s}$ as illustrated in Eq. (15). Since the mass flow rate $q_{s}$ is also directly dependent on the liquid flow velocity $u_{\llcorner}$as expressed by Eq. (16), the mass flow rate and the pressure drop in the pipe has to be calculated by iteration.

$$
\begin{array}{ll}
\mathrm{q}_{\mathrm{s}}=\mathrm{C}_{\mathrm{d}} \cdot \mathrm{A}_{\mathrm{h}} \cdot \sqrt{2\left(\mathrm{P}-\Delta \mathrm{P}\left(\mathrm{u}_{\mathrm{L}}, \mathrm{f}_{\mathrm{D}}\right)-\mathrm{P}_{\mathrm{a}}\right) \cdot \rho_{\mathrm{L}}} & {[\mathrm{kg} / \mathrm{s}]} \\
\mathrm{q}_{\mathrm{s}}=\rho_{\mathrm{L}} \cdot \mathrm{u}_{\mathrm{L}} \cdot \mathrm{A}_{\text {pipe }} & {[\mathrm{kg} / \mathrm{s}]}
\end{array}
$$

\subsubsection{Equivalent pool fire diameters}

For both cases, the quantification of a liquid flow from a tank through a hole or a pipe is time-dependent. A mass flow rate is computed at time $t$ with a hydraulic pressure depending on the height of liquid in the tank at that time $t$. Since this height $h_{L}(t)$ is decreasing with time, the corresponding mass flow rate $q_{s}(t)$ is decreasing with time as well. For the scope of both parametric analyses, 1000 different configurations were analysed during a time interval of 60 minutes with time step equal to $1 \mathrm{~min}$. Every minute, a mass flow rate $\mathrm{q}_{\mathrm{s}}\left(\mathrm{t}_{\mathrm{i}}\right)$ was computed by recurrence with the parameters determined based on the mass flow rate $\mathrm{q}_{\mathrm{s}}\left(\mathrm{t}_{\mathrm{i}-1}\right)$ previously determined. If the leaking fuel ignites, a pool fire develops, and an equivalent fire diameter can be calculated for each mass flow rate. Eq. (17) expresses the equivalent fire diameter as a function of the mass flow rate $q_{s}(\mathrm{~kg} / \mathrm{s})$ and of the limiting burning rate of the fuel $\dot{\mathrm{m}}_{\infty}\left(\mathrm{kg} / \mathrm{m}^{2} \mathrm{~s}\right)$.

$$
\mathrm{D}=\sqrt{\frac{\mathrm{q}_{\mathrm{s}}}{\dot{\mathrm{m}}_{\infty}} \cdot \frac{4}{\pi}} \quad[\mathrm{m}]
$$


Properties of some fuels are listed in Table 1. It has to be noted that the use of Eq. (17) safely assumes that the mass flow rate, computed at the time $t=0$, generates instantaneously a pool fire characterised by a non-zero diameter.

For the research discussed in this paper, it is assumed that a steel pipe-rack is exposed to a localised fire with constant diameter and lasting one hour. The time of an hour was selected based on the fact that the heat flux magnitude and the massivity of the steel profiles are such that the thermal equilibrium in terms of heat exchange can be attained in most cases. Furthermore, for the 1000 configurations analysed, the fire diameter, computed every minute, is decreasing with the mass flow rate. The decrease of the mass flow rate and fire diameter can be fast or slow depending on the parameters randomly assigned for each configuration. If the fire diameter decreases too fast, there is little interest to consider this fire scenario as relevant for the scope of the research because it may not be sufficiently strong, for enough time, to significantly impact the structure. Indeed, that would lead to a scenario in which the fire would be poorly supplied or extinguished too soon due to a mass flow rate becoming close or equal to zero. Such fire scenarios and their impact on a steel pipe-rack are consequently not investigated in this work. In this respect, analyses with a total variation of the diameter greater than $10 \%$ of the mean diameter are disregarded. It means that the selected fire scenarios present a diameter variation low enough to be represented with an equivalent constant diameter equal to the mean diameter. Finally, by considering only relevant fire scenarios for both cases, i.e. liquid flow through a hole and a pipe, it is possible to derive probability density functions (PDF) by considering the mean and the standard deviation of 1000 average fire diameters computed for each case. These functions are plotted in Figure 10 that illustrates the probabilities of observing a pool fire presenting different steady diameters, in case of leakage. Considering the assumptions and the scope of the parametric studies defined above, it can be observed that, in case of fuel leakage through a hole, the PDF is defined with a mean of $17.93 \mathrm{~m}$ and a standard deviation of $13.11 \mathrm{~m}$. Whereas in case of fuel leakage through pipe, the PDF is defined with a mean of $20.39 \mathrm{~m}$ and a standard deviation of $14.75 \mathrm{~m}$. As a result, only fire scenarios characterised by diameters in the range of $5 \mathrm{~m}-30 \mathrm{~m}$ were selected and, in order to simplify, a discrete sampling assuming uniform distribution was assumed in the remainder of the paper by considering 11 equal-spaced diameter values in order to limit the computational burden of the thermo-mechanical analyses. Nonetheless, these PDF can be useful for more refined future analyses. 


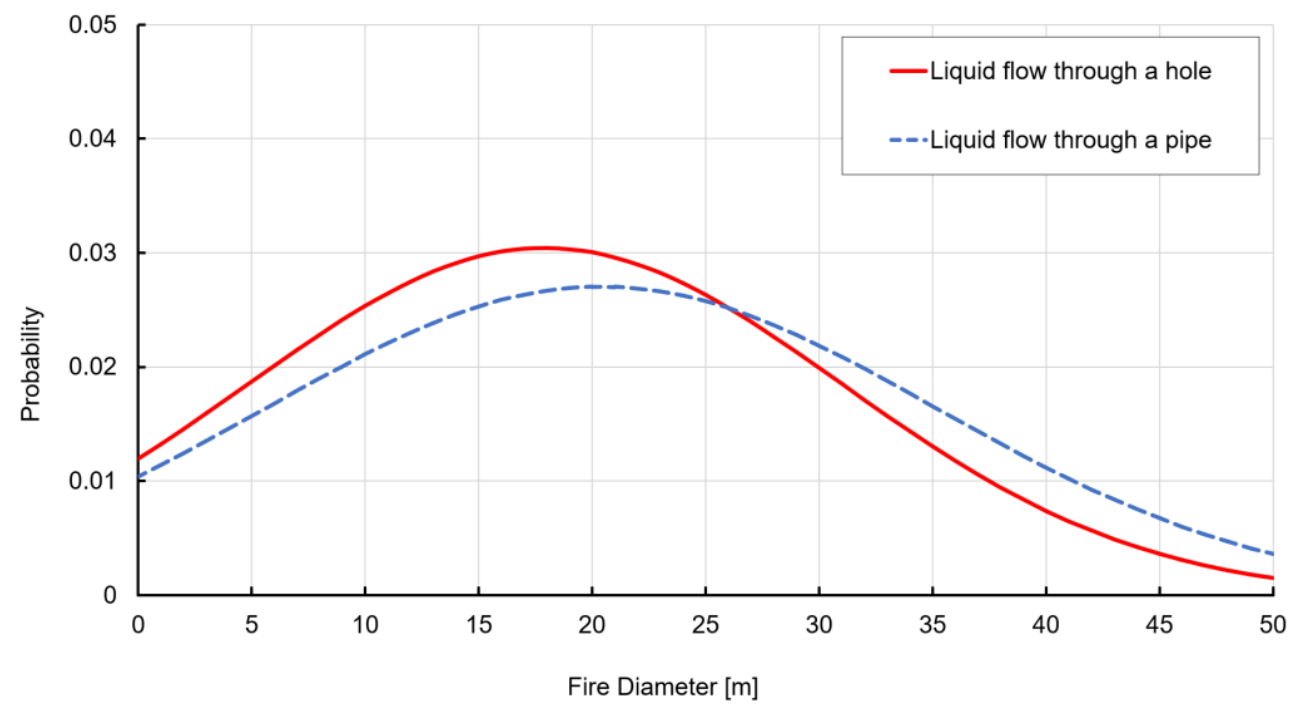

Figure 10 - Probability density functions of the pool fire diameter in case of fuel leakage and ignition

\subsection{Selection of fire scenarios}

To study the behaviour of the steel pipe-rack exposed to localised fires in a probabilistic way, a meaningful set of fire scenarios must be defined. The objective is to encompass plausible fire scenarios, that impact the structure with different levels of intensity. That means fire scenarios from causing low consequences to fires leading the entire structure to failure. Thus, besides the fire diameter described in Section 3.2, the fire scenarios were defined by varying other two parameters: i) the fuel and ii) the fire-structure distance. As shown, in Section 3.2, in petrochemical plants, pool fires can result from the ignition of a fuel contained in a cylindrical tank or from the ignition of a leaking fuel. 11 fire diameters, denoted $D$, varying between $5 \mathrm{~m}$ to $30 \mathrm{~m}$ with a step of $2.5 \mathrm{~m}$ were selected. Since petrochemical plants deal with various flammable products, in order to cover a wide range of different fuels and fire loads, 7 liquid fuels were selected for the definition of the fire scenarios. These 7 fuels are acetone, fuel oil, gasoline, kerosene, benzene, heptane and pentane, whose thermal properties are listed in Table 1. As a result, 77 different localised fires were defined and Table 4 summarizes the RHR computed for each localised fire according to Eq. (5) and Eq. (6). It is worth to point out that the LOCAFI model was compared against experimental data of kerosene pool fires as large as $50 \mathrm{~m}$ and characterised by RHR in the order of $3000 \mathrm{MW}$ [26]. 
Table 4 - Rate of heat release depending on fuels and fire diameters

\begin{tabular}{|c|c|c|c|c|c|c|c|c|c|c|c|}
\hline \multirow[t]{3}{*}{ Fuel } & \multicolumn{11}{|c|}{ Rate of heat release $[\mathrm{kW}]$} \\
\hline & \multicolumn{11}{|c|}{ Diameters [m] } \\
\hline & 5 & 7.5 & 10 & 12.5 & 15 & 17.5 & 20 & 22.5 & 25 & 27.5 & 30 \\
\hline Pentane & 91028 & 204812 & 364111 & 568923 & 819249 & 1115089 & 1456442 & 1843310 & 2275691 & 2753586 & 3276995 \\
\hline Heptane & 70867 & 159595 & 283733 & 443333 & 638399 & 868932 & 1134932 & 1436398 & 1773331 & 2145730 & 2553596 \\
\hline Benzene & 66926 & 150583 & 267703 & 418286 & 602332 & 819840 & 1070812 & 1355246 & 1673144 & 2024504 & 2409327 \\
\hline Kerosene & 53098 & 119671 & 212764 & 332444 & 478720 & 651591 & 851057 & 1077120 & 1329777 & 1609030 & 1914879 \\
\hline Gasoline & 47164 & 106182 & 188770 & 294954 & 424734 & 578109 & 755082 & 955650 & 1179815 & 1427577 & 1698934 \\
\hline Fuel Oil & 26497 & 59632 & 106013 & 165645 & 238529 & 324665 & 424052 & 536691 & 662582 & 801724 & 954117 \\
\hline Acetone & 19250 & 43313 & 77000 & 120313 & 173251 & 235814 & 308002 & 389815 & 481253 & 582316 & 693004 \\
\hline
\end{tabular}

As explained in Section 3.1, the distance separating a structure and a fire has a direct influence on the intensity of the radiative heat flux received by the structure. For the definition of the fire scenarios, 7 distances separating the edge of the fire and structure were considered. The 7 distances, denoted $d$, are: $0.5 \mathrm{~m}, 1 \mathrm{~m}, 2 \mathrm{~m}, 3 \mathrm{~m}, 4 \mathrm{~m}, 5 \mathrm{~m}$ and $6 \mathrm{~m}$, as depicted in Figure 11a. It has to be noted that the localised fires were positioned on the axis of the central moment resisting frame in order to have the most important impact on the structure. Fire scenarios with distances $\mathrm{d}$ close to $0 \mathrm{~m}$ have a significant impact on the structure while the ones close to $6 \mathrm{~m}$ are definitely less demanding, which explains why no further distance was considered. Eventually, by varying the values of the three parameters: fire diameter, fuel, and distance, 539 fire scenarios were defined and 539 thermo-mechanical analyses with the LOCAFI localised fire model as thermal input were performed in SAFIR. Figure 11b illustrates the 77 fire geometries which were investigated for the development of the probabilistic fire demand models. For each of them, the impact of the 7 fuels was analysed. 


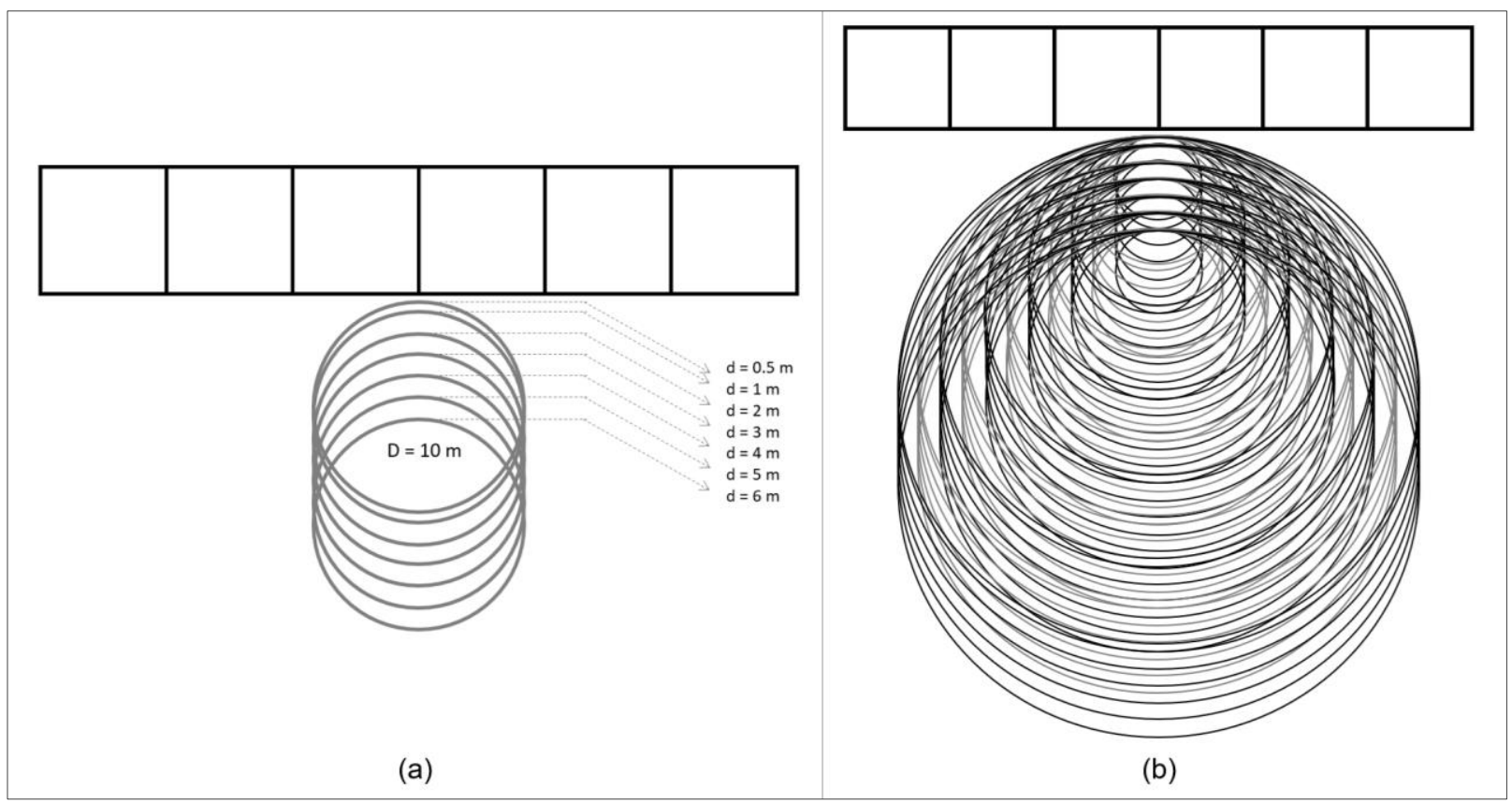

Figure 11 - Plan view of the pipe-rack exposed to: (a) Localised fires presenting a diameter of $10 \mathrm{~m}$ and different distances; (b) 77 fire geometries (11 diameters and 7 distances)

\section{Probabilistic fire demand analysis}

\subsection{Methods for developing fire fragility functions}

A fragility function expresses the probability that an engineering demand parameter (EDP) exceeds a structural limit state (LS) as a function of an intensity measure (IM). That probability is usually written in the following form

$$
\mathrm{P}(\mathrm{EDP}>\mathrm{LS} \mid \mathrm{IM})
$$

The aim is to develop fire fragility functions to be used in a probabilistic framework that will serve as a means for practitioners to probabilistically assess/design a pipe-rack structure subjected to localised fires. To build up fragility functions and to define the probability expressed in Eq. (18), it is necessary to develop a probabilistic demand model. In literature, several probabilistic seismic demand models (PSDM) can be found, whereas only few probabilistic fire demand models (PFDM) have been developed so far [35] [38]. Most PSDMs characterise the relation between EDP and IM based on results obtained through non-linear dynamic analysis. Three methods for obtaining PSDM are commonly adopted: cloud analysis (CA), incremental dynamic analysis (IDA) and multiple stripe analysis (MSA). In particular, CA considers a candidate EDP-IM pair as input data resulting from structural analyses and yields a probabilistic model based on linear regression assuming that EDPs are lognormally distributed when conditioned on the IM [42]. IDA consists in performing non-linear dynamic analyses by scaling an IM (typically a ground motion for PSDM) until the EDP exceeds a certain LS [53]. However, IDA is not the most appropriate method to be used for PFDM since scaling fire IM, such as fire load or heat flux, can rapidly lead to unrealistic fire scenarios. MSA differs from CA and IDA by the fact that it considers a discrete set of IMs. At each IM level, 
structural analyses are performed considering different ground motions for PSDM or different fire scenarios for PFDM. Structural response, i.e. the selected EDP, is recorded for each IM level forming stripes of data, and probabilities of exceedance can be straightforwardly computed for different LS [45] [40]. For instance, Shrivastava et al. [38] proposed a PFDM by investigating different intensity measures derived from a temperature-time curve using fire stripe analyses adapted from MSA.

On these premises, both CA and MSA methods seem to be appropriate methods for the development of an probabilistic fire demand model. However, in order to also consider IMs not necessarily leading to a representation of the EDP-IM pairs with stripes, it was decided to adopt the CA method for the development of the probabilistic fire demand model. Therefore, this method is further detailed hereafter.

\subsubsection{Cloud analysis}

In the CA all fire scenarios are run and based on thermo-mechanical results a cloud of points is plotted on an EDP vs IM chart. Assuming that the EDP follows a lognormal distribution when conditioned on the IM, which is a common assumption, it is possible to write the median EDP, i.e. ED̂P, as expressed in Eq. (19). Therefore, the conditional median of EDP given IM is linear in log-log space, as shown in Eq. (20), whereas the conditional dispersion of EDP given IM is constant. Thus, the resulting probabilistic demand model can be represented in linear and logarithmic forms as in Eq. (19) and (20), respectively, where $a=\exp (A)$ and $b=B$. A and B are parameters that can be determined from linear regression. With coefficients $a$ and $b$, the standard deviation of the linear regression error can be defined with Eq. (21). This term is also defined $\beta_{E D P I I M}$ as the dispersion of the EDP conditioned on IM. Considering the lognormal assumption, Eq. (19) and Eq. (21), Cornell et al. [42] defined the fragility function with the use of a lognormal cumulative distribution function as expressed in Eq. (22).

$$
\begin{aligned}
& E \widehat{D P P}=a I^{b} \\
& \operatorname{Ln}(E \widehat{D P})=A+B \operatorname{Ln}(I M) \\
& \sigma_{\operatorname{Ln}(E D P) \mid I M}=\beta_{E D P \mid I M}=\sqrt{\frac{\sum_{i=1}^{n}\left[\operatorname{Ln}\left(E_{D P}\right)-\operatorname{Ln}\left(E \widehat{E P} P_{i}\right)\right]^{2}}{n-2}} \\
& P(E D P>L S \mid I M)=1-\Phi\left(\frac{\ln \left(L S /\left(a I^{b}\right)\right)}{\beta_{E D P \mid I M}}\right)
\end{aligned}
$$

Eventually, different EDP-IM pairs can be considered and for each of them fire fragility functions can be derived considering different LS. Therefore Sections 4.3 and 4.2 aim at identifying relevant IMs and EDPs to build PFDMs through CA. 


\subsection{Intensity measures}

An intensity measure (IM) aims to characterise the severity of a fire scenario. In probabilistic structural fire engineering, the main IMs identified up to now in literature are relative to compartment fires, such as maximum fire temperature, fire duration, time to maximum fire temperature, area under the fire temperature-time curve, cumulative incident radiation and fire load. In that sense, most of the IMs used for compartment fires cannot be directly applied to localised fires. Thus, 7 IMs are here proposed in Table 5. $3 \mathrm{IMs}$ are the parameters defining the fire scenarios, i.e. D, $d$ and $q$, while $4 \mathrm{IMs}$ are functions of them. The parameter q is referred to as the RHR density and it is defined based on Eq. (5) and Eq. (6) where the mass burning rate $\dot{m}_{b}$ can be approximated to $\dot{\mathrm{m}}_{\infty}$ with fairly good accuracy for $\mathrm{D}>1 \mathrm{~m}$. That is appropriate to characterise the power associated to a fuel. The fire position $L$ in the ratio $L / D$ corresponds to the distance separating the structure from the centre of the fire and it is simply derived from distance $d$ and fire diameter $\mathrm{D}$. The maximum average radiative heat flux impinging the structure $\mathrm{HF}_{\text {avg }}$ considered here as IM was evaluated for each of the 539 fire scenarios with the analytical LOCAFI model [26].

Table 5 - Intensity measures

\begin{tabular}{ccccc}
\hline IM & Name & Unit & Function & Formula \\
\hline$D$ & Fire diameter & $m$ & $f(D)$ & - \\
$d$ & Structure fire distance & $m$ & $f(d)$ & - \\
$q$ & Equivalent RHR density of the fuel & $M W / m^{2}$ & $f(q)$ & $\dot{m}_{\infty} \Delta H_{c}$ \\
$L / D$ & Fire position-fire diameter ratio & - & $f(D, d)$ & $(d+D / 2) / D$ \\
$L_{F 1}$ & Flame length & $m$ & $f(D, q)$ & see Eq. (1) \\
$H F_{\text {avg }}$ & Maximum average heat flux impinging the & $k W / m^{2}$ & $f(D, d, q)$ & see [26] \\
$d / L_{F 1}$ & Structure & - & $f(D, d, q)$ & $d /[$ Eq. (1)] \\
\hline
\end{tabular}

\subsection{Engineering demand parameters}

In order to build a probabilistic demand model, the selection of appropriate engineering demand parameters (EDP) that are able to describe the structural response is paramount. In fact, an EDP aims to be a good indicator of the structural response under a certain type of action. For steel buildings exposed to compartment fires, maximum member temperature and member vertical deflections are usually identified as relevant EDPs. Nevertheless, for the purpose of this work, other EDPs may be relevant. Indeed, the temperature in the elements may vary significantly in the cross section and along their longitudinal axis owing to non-uniform thermal exposure. Therefore, it may be difficult to express the global structural response in terms of a steel temperature value. Moreover, vertical deflections may be small due to the fact that the fire does not engulf any structural element. Thus, in order to identify suitable EDPs considering localised fire located beside the structure, several thermo-mechanical analyses were performed. In particular, 130 analyses out of the 539 scenarios, were deeply investigated. These 130 cases are among the ones causing major internal actions and displacements. For 59 cases, the structure failed within 60 minutes of analysis, whereas for the 71 other cases, the structure survived the whole analysis. 
Based on these analyses, 5 possible EDPs for the case under study were identified and reported in Table 6.

Table 6 - Engineering demand parameters

\begin{tabular}{ccc}
\hline EDP & Name & Unit \\
\hline ISDR & Interstorey drift ratio & $\%$ \\
$\mathrm{~N}_{Z}$ & Axial load & $\mathrm{kN}$ \\
$\mathrm{M}_{\mathrm{X}}$ & Bending moment & $\mathrm{kNm}$ \\
$\mathrm{T}_{\mathrm{MAX}}$ & Maximum average temperature & ${ }^{\circ} \mathrm{C}$ \\
$\mathrm{T}_{\text {AVG }}$ & Average temperature & ${ }^{\circ} \mathrm{C}$ \\
\hline
\end{tabular}

For each of the 130 analyses, ISDR, $\mathrm{N}_{z}$ and $\mathrm{M}_{\mathrm{x}}$ were respectively the maximum interstorey drift ratio, axial load and bending moment observed within the structure. $T_{\text {MAX }}$ was the maximum average temperature computed within the whole structure, while $\mathrm{T}_{\mathrm{AVG}}$ was the average temperature within the highly stressed beam element. These EDPs were evaluated and compared based on their ability to characterise the structural response and it appeared that the ISDR was the most suitable EDP. In fact, it offers several advantages: i) it only considers the structural response, independently from the fire scenario and it is representative of the fire scenarios that cause significant lateral displacement; ii) it is straightforward to evaluate and to compare with other structural- and load configurations and iii) it can be associated with specific structural damage states as referred in literature. In this respect, the American seismic rehabilitation prestandard [54] associates, for steel moment resisting frames, an ISDR equal to $5 \%$ and an ISDR equal to $2.5 \%$ that are representative of a near collapse limit state and life safety limit state, respectively. Both can be considered as ultimate limit states. Considering thermal- and mechanical loads applied to the pipe-rack, near collapse limit state refers to a state where the structure is severely heated so that a small increase of thermal- or mechanical loads would lead the structure to failure. Life safety limit state refers to a state where the structure is heated in such a way that it is in a significant deformative state, but it still has a margin of bearing capacity to support additional thermal- and/or mechanical loads. These ISDR values of $5 \%$ and $2.5 \%$ were therefore adopted in the probabilistic fire demand model framework as limit states. It is worth to point out that differently from the seismic case where the ISDR is widely used as EDP, for structural fire applications some care has to be taken. For instance, in a multistorey structure subjected to a seismic event the whole floor is typically subjected to the same ISDR value because of the rigid diaphragm assumption, but in case of a localised fire the elements may exhibit differential ISDR at the same floor. Thus, in a seismic event it can be considered as global EDP, whereas in a localised fire scenario it may be considered as either global or local EDP depending on the size of the fire with respect to the structure. In this study, the ISDR can be assumed as global EDP because it can be related to damage and collapse of a significant part of the pipe-rack. 


\subsection{Results of the numerical analyses}

As explained in sections 2.2 and 3.1, numerical analyses were performed with SAFIR. The analyses were run for 60 minutes, a time during which the different structural members received a constant heat flux so that they could reach their thermal equilibrium as for steel temperature.

The impact of the localised fire on structural members was investigated for the entire pipe-rack. Figure 12a depicts the pipe-rack after a 60 min exposure to a heptane pool fire characterised by a diameter of $20 \mathrm{~m}$ and located $2 \mathrm{~m}$ away from the structure. The thermal effect of the localised fire and the horizontal loads applied in the positive y-direction (see Figure 12a) induced significant horizontal displacements. These horizontal displacements increased during the fire owing to thermal bowing and loss of stiffness of steel and consequently second order effects became not negligible. Indeed, the impact of the localised fire had two major effects on structural members: i) axial dilatation and thermal bowing of the members, that are partially restrained; thus, causing internal forces and ii) decrease in load bearing capacity due to loss of strength and stiffness of steel at elevated temperature. As expected, the fire scenarios under consideration induced significant non-uniform heating in the cross-sections, as shown in Figure $12 \mathrm{~b}$ and 12c, that depict the temperature fields within the cross sections located at $5 \mathrm{~m}$ of columns $\mathrm{A} 4$ and $\mathrm{A} 3$, that are respectively $2 \mathrm{~m}$ and $3.41 \mathrm{~m}$ distant from the fire. Among the 539 fire scenarios investigated, 59 cases led the pipe-rack to collapse. In this respect, Figure 13 depicts the failure mechanism of the structure, which involves the loss of stability of the central frame. The displacements were maximal at the top of the structure ( $9 \mathrm{~m}$ high) but the highest interstorey drift ratios (ISDR) were observed transversally at the first level of the columns. Table 7 reports on the maximum ISDRs observed for each of the 539 analyses and provides an overview of the influence of the basic fire parameters $D, d$ and $q$ on the structural response. As expected, the increase in ISDR is generally related to an increase in fire diameter D and/or to a reduction in the fire-structure distance $d$ and/or to a more hazardous fuel in terms of higher mass burning rate or heat of combustion. In Table 7, green cells indicate ISDR values between $2.5 \%$ and $5 \%$ and red cells indicate values greater than $5 \%$. In most cases numerical failure was observed and the value of ISDR at the time step before structural runaway was considered, which was always larger than $5 \% .11$ thermo-mechanical analyses exhibited ISDR $>5 \%$ but did not experience failure and it was checked that all of them were in a state of near collapse by slightly increasing the loads that led to structural failure. It should be noted, that the dimensions of the larger fire scenarios are quite big with respect to the structure dimensions; thus, their overall impact on the structure is not significantly different from each other. However, small differences in the geometry and consequently in configuration factors may affect the heating of certain parts of the structure due to shadow effects that can lead to differences in the results, as especially highlighted for $\mathrm{d}=0.5 \mathrm{~m}$ and $\mathrm{d}=1 \mathrm{~m}$.

Based on the 539 results of the numerical analysis, using the ISDR as EDP, and by considering the IM candidates listed in Table 5, PFDMs were developed through CA. For each of the 7 candidate IMs, Figure 14 depicts the PFDMs derived by means of CA in linear and logarithmic space. The dispersion value $\beta_{E D P \mid I M}$ of the EDP conditioned on the IM and the coefficients $a$ and $b$ obtained through linear regression are also indicated for each candidate IMs. In particular, it is possible to note that for IMs such that D, $d, q$, the results are plotted with stripes. As described in Section 4.5, all IM candidates are efficient, because they exhibit dispersion values lower than 0.3 . 


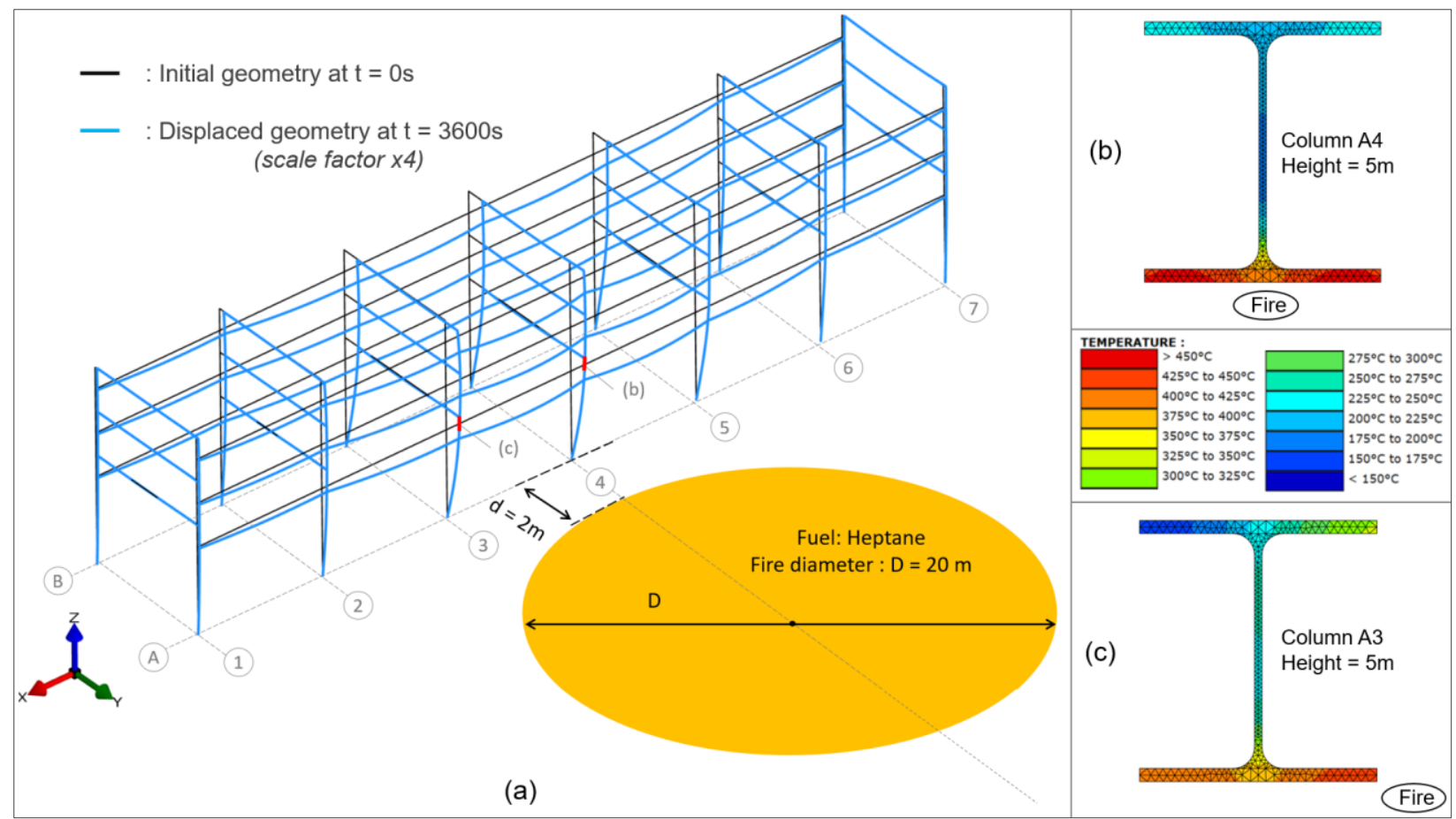

Figure 12 - Steel pipe-rack exposed to fire scenario “D=20m - d=2m - Fuel=Heptane" for 60 min: (a) Initial and displaced shape of the structure; (b) Temperature field in cross section of column $A 4(h=5 m)$; (c) Temperature field within in cross section column $\mathrm{A} 3(\mathrm{~h}=5 \mathrm{~m})$

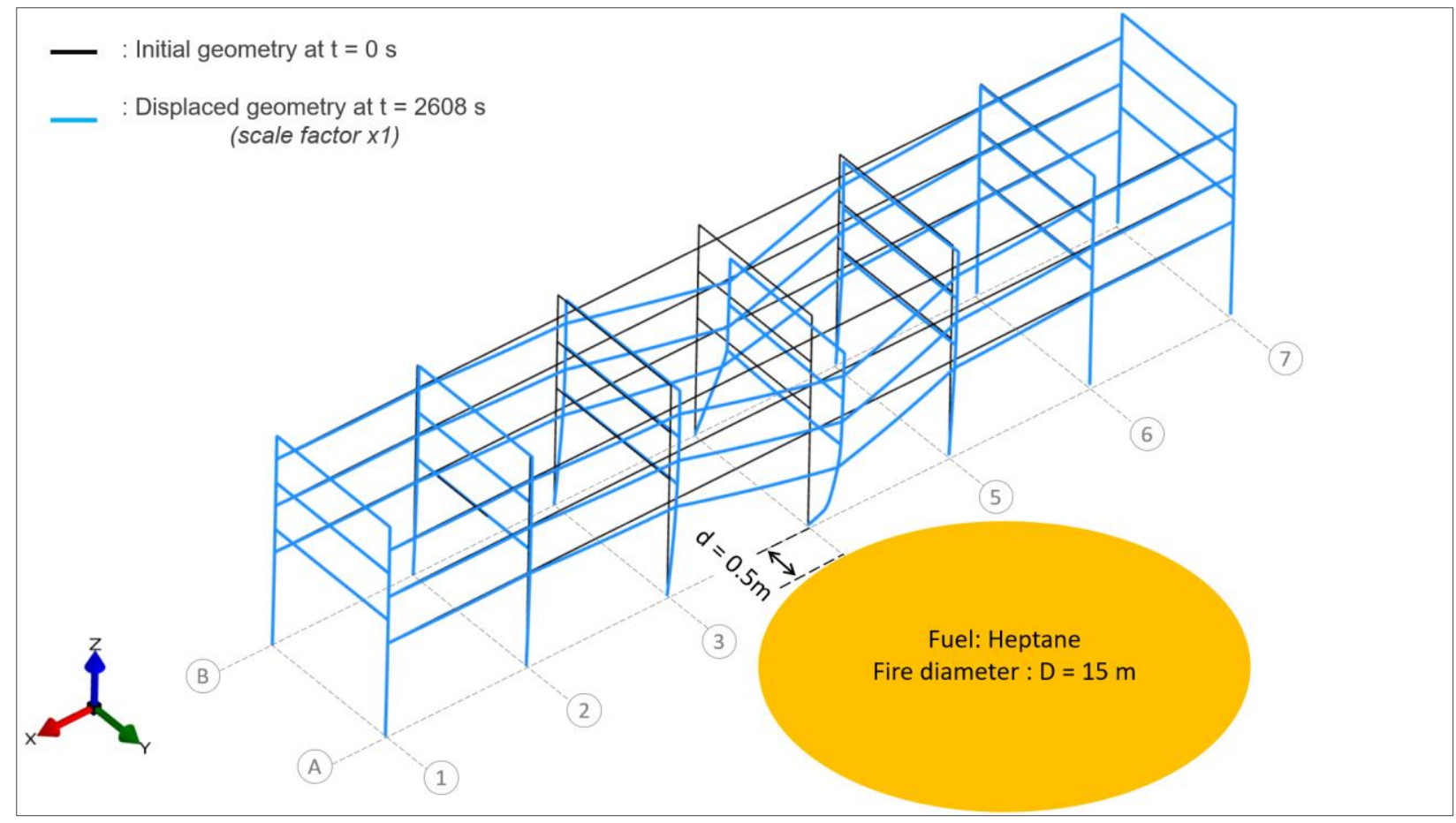

Figure 13 - Steel pipe-rack exposed to fire scenario "D=15m - d=0.5m - Fuel=Heptane": Failure of the structure after $2608 \mathrm{~s}$ 
Table 7 - Maximum interstorey drift ratios observed for the 539 fire scenarios

\begin{tabular}{|c|c|c|c|c|c|c|c|c|c|c|c|c|}
\hline \multirow{3}{*}{$\begin{array}{c}\text { Distance } \\
\mathrm{d}[\mathrm{m}]\end{array}$} & \multirow{3}{*}{ Fuels } & \multicolumn{11}{|c|}{ Interstorey drift ratios } \\
\hline & & \multicolumn{11}{|c|}{ Fire diameters D [m] } \\
\hline & & 5 & 7.5 & 10 & 12.5 & 15 & 17.5 & 20 & 22.5 & 25 & 27.5 & 30 \\
\hline 6 & Pentane & $1.79 \%$ & $2.43 \%$ & $2.89 \%$ & $3.21 \%$ & $3.43 \%$ & $3.58 \%$ & $3.70 \%$ & $3.77 \%$ & $3.83 \%$ & $3.87 \%$ & $3.90 \%$ \\
\hline 6 & Heptane & $1.68 \%$ & $2.31 \%$ & $2.77 \%$ & $3.10 \%$ & $3.33 \%$ & $3.49 \%$ & $3.62 \%$ & $3.70 \%$ & $3.77 \%$ & $3.81 \%$ & $3.85 \%$ \\
\hline 6 & Benzene & $1.66 \%$ & $2.27 \%$ & $2.74 \%$ & $3.07 \%$ & $3.30 \%$ & $3.47 \%$ & $3.60 \%$ & $3.68 \%$ & $3.75 \%$ & $3.80 \%$ & $3.84 \%$ \\
\hline 6 & Kerosene & $1.56 \%$ & $2.14 \%$ & $2.61 \%$ & $2.95 \%$ & $3.19 \%$ & $3.36 \%$ & $3.49 \%$ & $3.59 \%$ & $3.67 \%$ & $3.72 \%$ & $3.77 \%$ \\
\hline 6 & Gasoline & $1.51 \%$ & $2.07 \%$ & $2.53 \%$ & $2.87 \%$ & $3.11 \%$ & $3.29 \%$ & $3.42 \%$ & $3.53 \%$ & $3.61 \%$ & $3.67 \%$ & $3.72 \%$ \\
\hline 6 & Fuel Oil & $1.27 \%$ & $1.69 \%$ & $2.09 \%$ & $2.40 \%$ & $2.65 \%$ & $2.84 \%$ & $2.98 \%$ & $3.10 \%$ & $3.19 \%$ & $3.26 \%$ & $3.32 \%$ \\
\hline 6 & Acetone & $1.16 \%$ & $1.48 \%$ & $1.81 \%$ & $2.09 \%$ & $2.31 \%$ & $2.48 \%$ & $2.62 \%$ & $2.73 \%$ & $2.81 \%$ & $2.88 \%$ & $2.94 \%$ \\
\hline 5 & Pentane & $2.03 \%$ & $2.71 \%$ & $3.16 \%$ & $3.46 \%$ & $3.66 \%$ & $3.79 \%$ & $3.88 \%$ & $3.93 \%$ & $3.96 \%$ & $4.00 \%$ & $4.04 \%$ \\
\hline 5 & Heptane & $1.91 \%$ & $2.58 \%$ & $3.04 \%$ & $3.35 \%$ & $3.57 \%$ & $3.71 \%$ & $3.81 \%$ & $3.87 \%$ & $3.92 \%$ & $3.96 \%$ & $4.00 \%$ \\
\hline 5 & Benzene & $1.88 \%$ & $2.55 \%$ & $3.01 \%$ & $3.32 \%$ & $3.54 \%$ & $3.69 \%$ & $3.79 \%$ & $3.86 \%$ & $3.90 \%$ & $3.94 \%$ & $3.99 \%$ \\
\hline 5 & Kerosene & $1.76 \%$ & $2.41 \%$ & $2.88 \%$ & $3.20 \%$ & $3.43 \%$ & $3.59 \%$ & $3.70 \%$ & $3.78 \%$ & $3.83 \%$ & $3.88 \%$ & $3.92 \%$ \\
\hline 5 & Gasoline & $1.70 \%$ & $2.33 \%$ & $2.80 \%$ & $3.13 \%$ & $3.36 \%$ & $3.53 \%$ & $3.64 \%$ & $3.73 \%$ & $3.79 \%$ & $3.83 \%$ & $3.88 \%$ \\
\hline 5 & Fuel Oil & $1.40 \%$ & $1.91 \%$ & $2.33 \%$ & $2.66 \%$ & $2.90 \%$ & $3.08 \%$ & $3.21 \%$ & $3.32 \%$ & $3.40 \%$ & $3.46 \%$ & $3.52 \%$ \\
\hline 5 & Acetone & $1.25 \%$ & $1.65 \%$ & $2.02 \%$ & $2.32 \%$ & $2.55 \%$ & $2.72 \%$ & $2.85 \%$ & $2.95 \%$ & $3.03 \%$ & $3.09 \%$ & $3.14 \%$ \\
\hline 4 & Pentane & $2.33 \%$ & $3.00 \%$ & $3.44 \%$ & $3.73 \%$ & $3.90 \%$ & $4.00 \%$ & $4.05 \%$ & $4.08 \%$ & $4.11 \%$ & $4.25 \%$ & $4.32 \%$ \\
\hline 4 & Heptane & $2.20 \%$ & $2.88 \%$ & $3.33 \%$ & $3.63 \%$ & $3.82 \%$ & $3.94 \%$ & $4.00 \%$ & $4.04 \%$ & $4.08 \%$ & $4.11 \%$ & $4.20 \%$ \\
\hline 4 & Benzene & $2.16 \%$ & $2.85 \%$ & $3.30 \%$ & $3.61 \%$ & $3.80 \%$ & $3.92 \%$ & $3.99 \%$ & $4.03 \%$ & $4.06 \%$ & $4.09 \%$ & $4.16 \%$ \\
\hline 4 & Kerosene & $2.03 \%$ & $2.71 \%$ & $3.17 \%$ & $3.49 \%$ & $3.70 \%$ & $3.83 \%$ & $3.91 \%$ & $3.96 \%$ & $4.01 \%$ & $4.04 \%$ & $4.07 \%$ \\
\hline 4 & Gasoline & $1.95 \%$ & $2.63 \%$ & $3.09 \%$ & $3.41 \%$ & $3.63 \%$ & $3.77 \%$ & $3.86 \%$ & $3.92 \%$ & $3.97 \%$ & $4.00 \%$ & $4.04 \%$ \\
\hline 4 & Fuel Oil & $1.57 \%$ & $2.17 \%$ & $2.61 \%$ & $2.94 \%$ & $3.18 \%$ & $3.34 \%$ & $3.46 \%$ & $3.55 \%$ & $3.62 \%$ & $3.67 \%$ & $3.72 \%$ \\
\hline 4 & Acetone & $1.38 \%$ & $1.87 \%$ & $2.28 \%$ & $2.58 \%$ & $2.81 \%$ & $2.98 \%$ & $3.10 \%$ & $3.19 \%$ & $3.26 \%$ & $3.32 \%$ & $3.36 \%$ \\
\hline 3 & Pentane & $2.66 \%$ & $3.33 \%$ & $3.76 \%$ & $4.03 \%$ & $4.17 \%$ & $4.21 \%$ & $4.22 \%$ & $4.28 \%$ & $4.54 \%$ & $4.68 \%$ & $4.86 \%$ \\
\hline 3 & Heptane & $2.53 \%$ & $3.21 \%$ & $3.66 \%$ & $3.94 \%$ & $4.10 \%$ & $4.16 \%$ & $4.19 \%$ & $4.20 \%$ & $4.35 \%$ & $4.49 \%$ & $4.62 \%$ \\
\hline 3 & Benzene & $2.50 \%$ & $3.18 \%$ & $3.63 \%$ & $3.91 \%$ & $4.07 \%$ & $4.15 \%$ & $4.18 \%$ & $4.19 \%$ & $4.31 \%$ & $4.44 \%$ & $4.58 \%$ \\
\hline 3 & Kerosene & $2.35 \%$ & $3.04 \%$ & $3.50 \%$ & $3.80 \%$ & $3.98 \%$ & $4.07 \%$ & $4.12 \%$ & $4.15 \%$ & $4.16 \%$ & $4.27 \%$ & $4.40 \%$ \\
\hline 3 & Gasoline & $2.27 \%$ & $2.96 \%$ & $3.42 \%$ & $3.73 \%$ & $3.92 \%$ & $4.02 \%$ & $4.08 \%$ & $4.12 \%$ & $4.14 \%$ & $4.17 \%$ & $4.30 \%$ \\
\hline 3 & Fuel Oil & $1.81 \%$ & $2.47 \%$ & $2.93 \%$ & $3.25 \%$ & $3.48 \%$ & $3.63 \%$ & $3.72 \%$ & $3.80 \%$ & $3.85 \%$ & $3.89 \%$ & $3.92 \%$ \\
\hline 3 & Acetone & $1.56 \%$ & $2.14 \%$ & $2.57 \%$ & $2.89 \%$ & $3.11 \%$ & $3.26 \%$ & $3.37 \%$ & $3.46 \%$ & $3.51 \%$ & $3.56 \%$ & $3.60 \%$ \\
\hline 2 & Pentane & $3.02 \%$ & $3.69 \%$ & $4.15 \%$ & $4.40 \%$ & $4.46 \%$ & $4.41 \%$ & $4.47 \%$ & $5.02 \%$ & $5.39 \%$ & $5.31 \%$ & $5.54 \%$ \\
\hline 2 & Heptane & $2.89 \%$ & $3.57 \%$ & $4.04 \%$ & $4.31 \%$ & $4.40 \%$ & $4.39 \%$ & $4.35 \%$ & $4.70 \%$ & $5.10 \%$ & $5.56 \%$ & $5.45 \%$ \\
\hline 2 & Benzene & $2.85 \%$ & $3.53 \%$ & $4.00 \%$ & $4.28 \%$ & $4.38 \%$ & $4.38 \%$ & $4.34 \%$ & $4.63 \%$ & $5.00 \%$ & $5.31 \%$ & $5.34 \%$ \\
\hline 2 & Kerosene & $2.71 \%$ & $3.39 \%$ & $3.87 \%$ & $4.16 \%$ & $4.30 \%$ & $4.33 \%$ & $4.32 \%$ & $4.29 \%$ & $4.68 \%$ & $4.86 \%$ & $4.89 \%$ \\
\hline 2 & Gasoline & $2.62 \%$ & $3.31 \%$ & $3.79 \%$ & $4.09 \%$ & $4.24 \%$ & $4.29 \%$ & $4.30 \%$ & $4.28 \%$ & $4.53 \%$ & $4.70 \%$ & $4.74 \%$ \\
\hline 2 & Fuel Oil & $2.12 \%$ & $2.81 \%$ & $3.28 \%$ & $3.61 \%$ & $3.82 \%$ & $3.94 \%$ & $4.02 \%$ & $4.07 \%$ & $4.10 \%$ & $4.13 \%$ & $4.16 \%$ \\
\hline 2 & Acetone & $1.81 \%$ & $2.45 \%$ & $2.90 \%$ & $3.22 \%$ & $3.44 \%$ & $3.59 \%$ & $3.68 \%$ & $3.76 \%$ & $3.81 \%$ & $3.85 \%$ & $3.89 \%$ \\
\hline 1 & Pentane & $3.37 \%$ & $4.10 \%$ & $4.65 \%$ & $5.33 \%$ & $4.96 \%$ & $4.55 \%$ & $5.47 \%$ & $5.29 \%$ & $5.28 \%$ & $5.27 \%$ & $5.27 \%$ \\
\hline 1 & Heptane & $3.24 \%$ & $3.97 \%$ & $4.51 \%$ & $4.86 \%$ & $4.84 \%$ & $4.58 \%$ & $5.27 \%$ & $5.41 \%$ & $5.20 \%$ & $5.38 \%$ & $5.41 \%$ \\
\hline 1 & Benzene & $3.20 \%$ & $3.93 \%$ & $4.47 \%$ & $4.81 \%$ & $4.81 \%$ & $4.59 \%$ & $5.09 \%$ & $5.31 \%$ & $5.26 \%$ & $5.19 \%$ & $5.20 \%$ \\
\hline 1 & Kerosene & $3.06 \%$ & $3.79 \%$ & $4.32 \%$ & $4.64 \%$ & $4.72 \%$ & $4.59 \%$ & $4.67 \%$ & $5.37 \%$ & $5.37 \%$ & $5.24 \%$ & $5.33 \%$ \\
\hline 1 & Gasoline & $2.97 \%$ & $3.70 \%$ & $4.23 \%$ & $4.56 \%$ & $4.66 \%$ & $4.58 \%$ & $4.48 \%$ & $5.16 \%$ & $5.38 \%$ & $5.40 \%$ & $5.30 \%$ \\
\hline 1 & Fuel Oil & $2.46 \%$ & $3.16 \%$ & $3.67 \%$ & $4.03 \%$ & $4.24 \%$ & $4.32 \%$ & $4.34 \%$ & $4.33 \%$ & $4.32 \%$ & $4.57 \%$ & $4.67 \%$ \\
\hline 1 & Acetone & $2.09 \%$ & $2.77 \%$ & $3.26 \%$ & $3.60 \%$ & $3.83 \%$ & $3.97 \%$ & $4.04 \%$ & $4.09 \%$ & $4.12 \%$ & $4.12 \%$ & $4.14 \%$ \\
\hline 0.5 & Pentane & $3.50 \%$ & $4.28 \%$ & $5.35 \%$ & $5.14 \%$ & $5.10 \%$ & $5.50 \%$ & $5.39 \%$ & $5.39 \%$ & $5.23 \%$ & $5.06 \%$ & $5.45 \%$ \\
\hline 0.5 & Heptane & $3.38 \%$ & $4.15 \%$ & $4.88 \%$ & $5.16 \%$ & $5.13 \%$ & $4.77 \%$ & $5.39 \%$ & $5.34 \%$ & $5.09 \%$ & $5.33 \%$ & $5.40 \%$ \\
\hline 0.5 & Benzene & $3.34 \%$ & $4.11 \%$ & $4.81 \%$ & $5.27 \%$ & $5.14 \%$ & $4.67 \%$ & $5.23 \%$ & $5.12 \%$ & $5.32 \%$ & $5.25 \%$ & $5.19 \%$ \\
\hline 0.5 & Kerosene & $3.20 \%$ & $3.97 \%$ & $4.58 \%$ & $5.34 \%$ & $5.25 \%$ & $4.62 \%$ & $5.43 \%$ & $5.32 \%$ & $5.25 \%$ & $5.36 \%$ & $5.53 \%$ \\
\hline 0.5 & Gasoline & $3.12 \%$ & $3.88 \%$ & $4.48 \%$ & $4.95 \%$ & $5.01 \%$ & $4.64 \%$ & $4.39 \%$ & $5.31 \%$ & $5.40 \%$ & $5.22 \%$ & $5.43 \%$ \\
\hline 0.5 & Fuel Oil & $2.60 \%$ & $3.34 \%$ & $3.89 \%$ & $4.26 \%$ & $4.45 \%$ & $4.48 \%$ & $4.44 \%$ & $4.39 \%$ & $4.77 \%$ & $5.07 \%$ & $5.58 \%$ \\
\hline 0.5 & Acetone & $2.23 \%$ & $2.93 \%$ & $3.44 \%$ & $3.81 \%$ & $4.03 \%$ & $4.15 \%$ & $4.20 \%$ & $4.22 \%$ & $4.21 \%$ & $4.21 \%$ & $4.19 \%$ \\
\hline
\end{tabular}


(a)

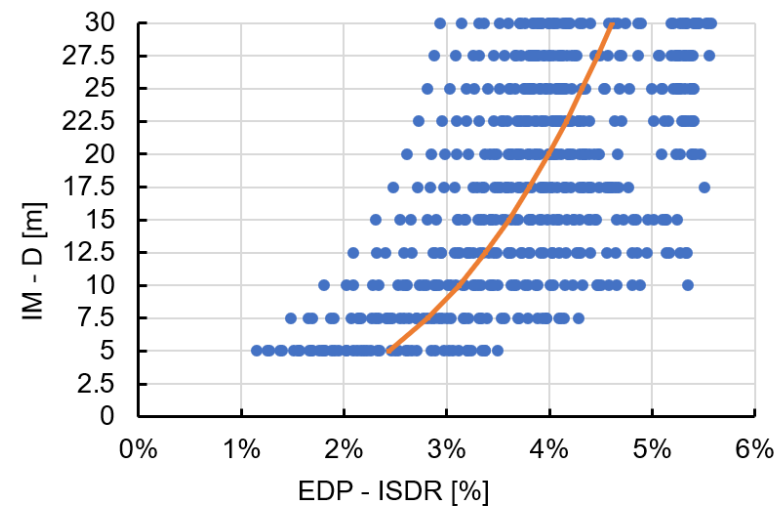

(b)

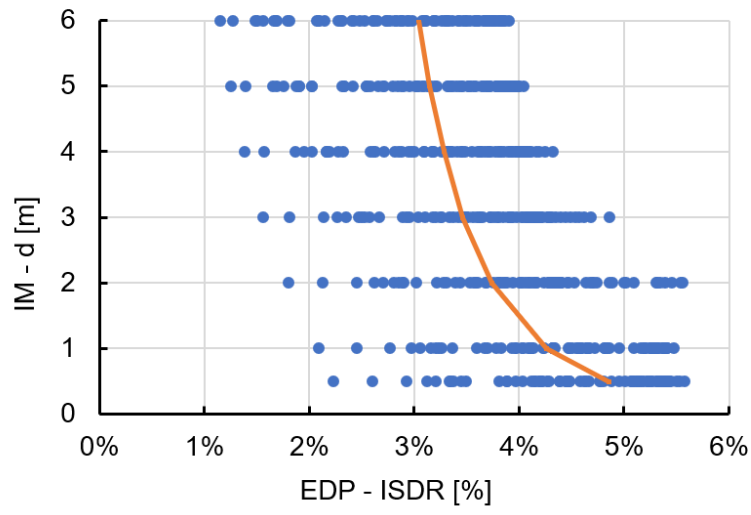

(c)

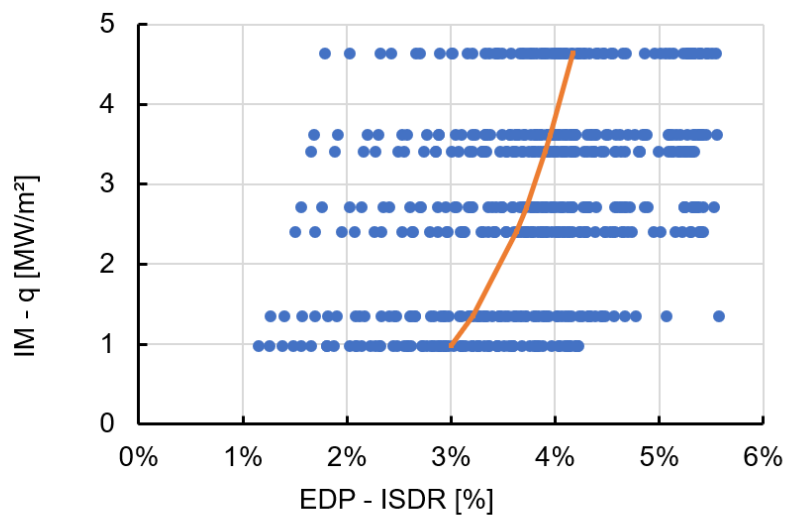

(d)

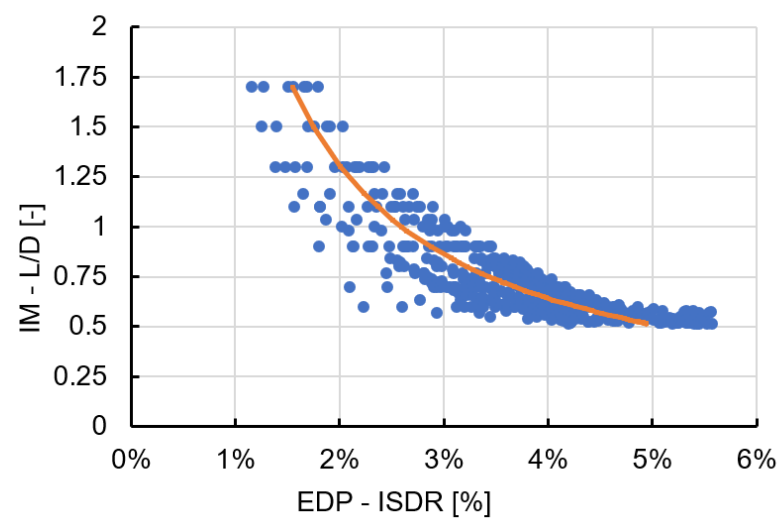

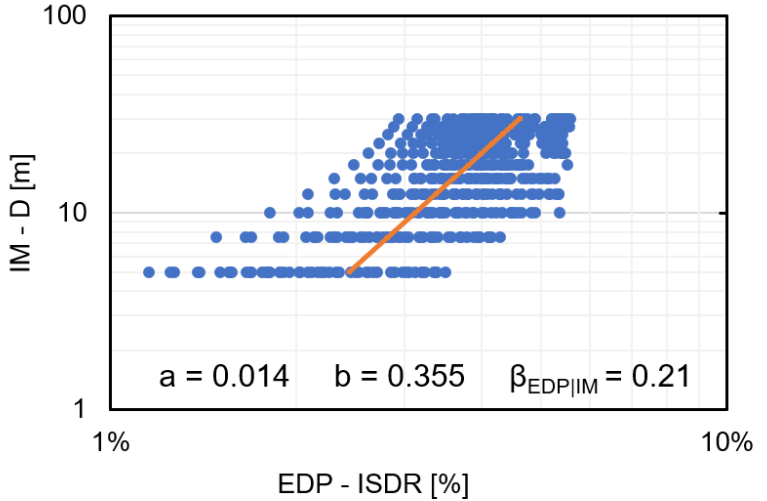
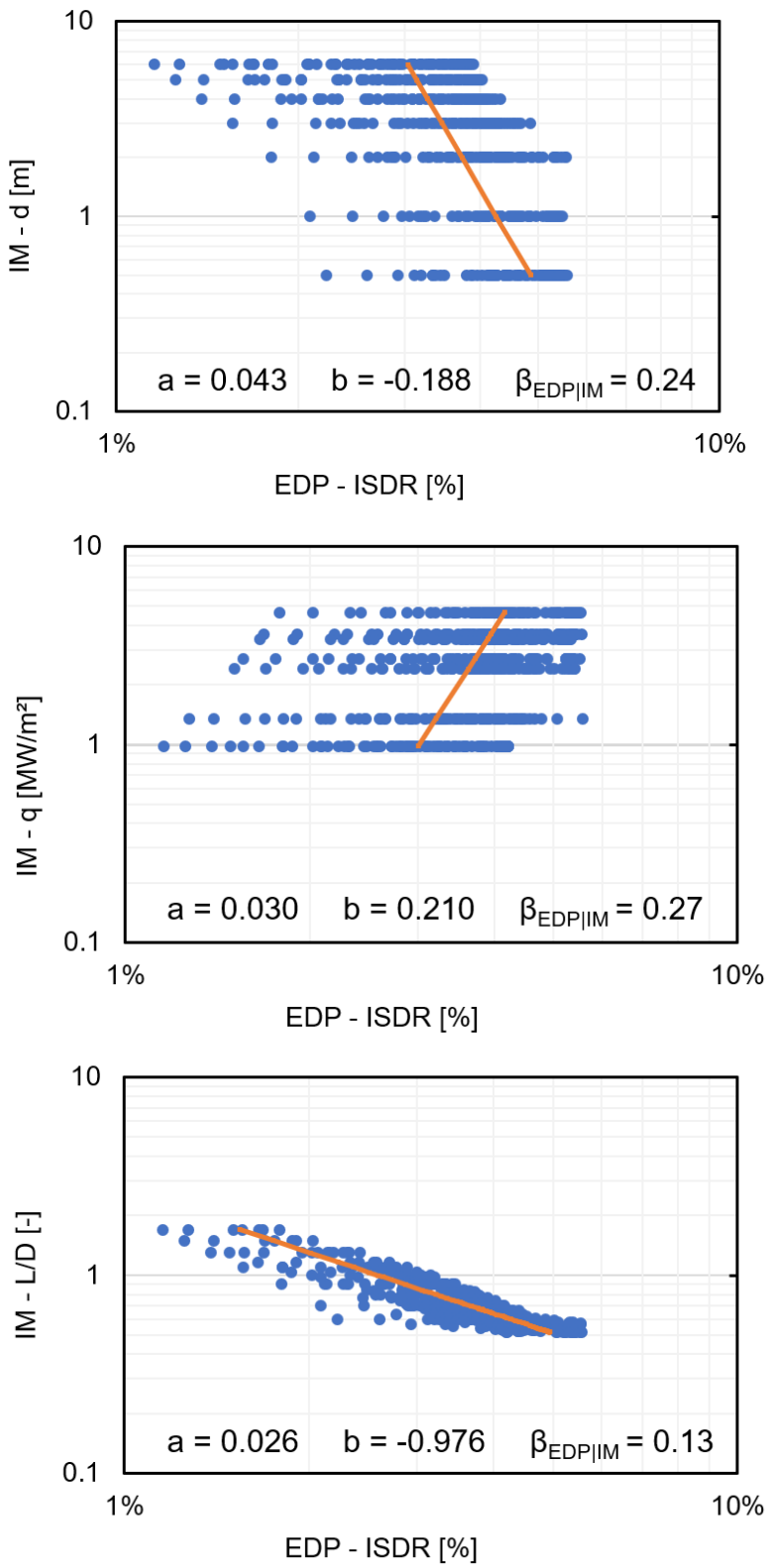
(e)
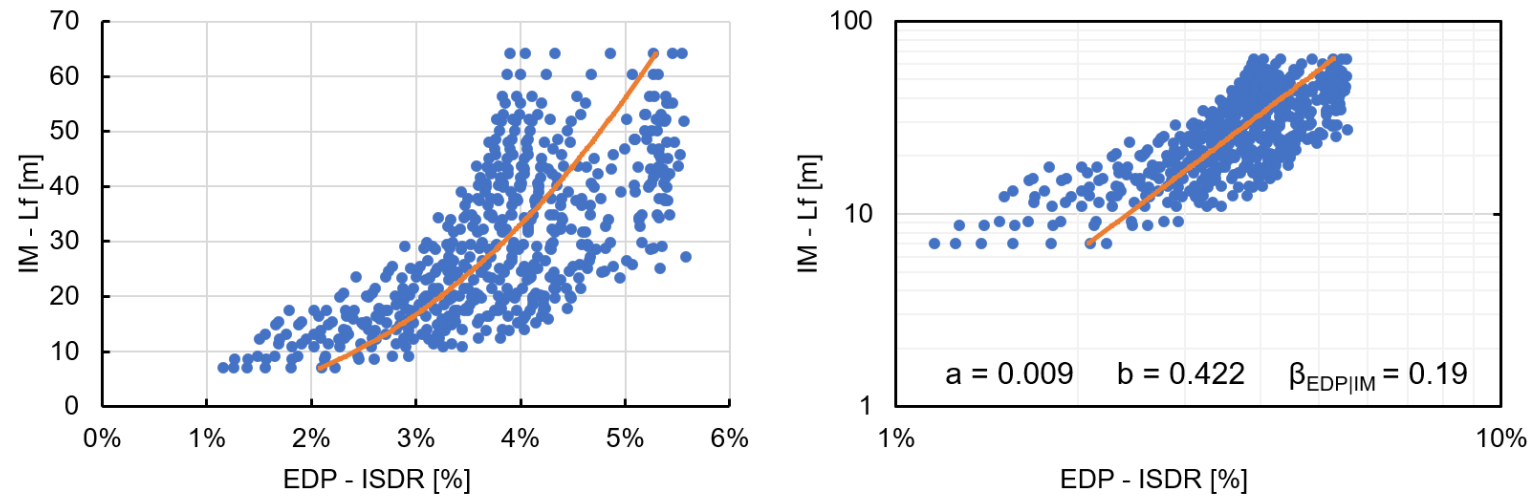

(f)
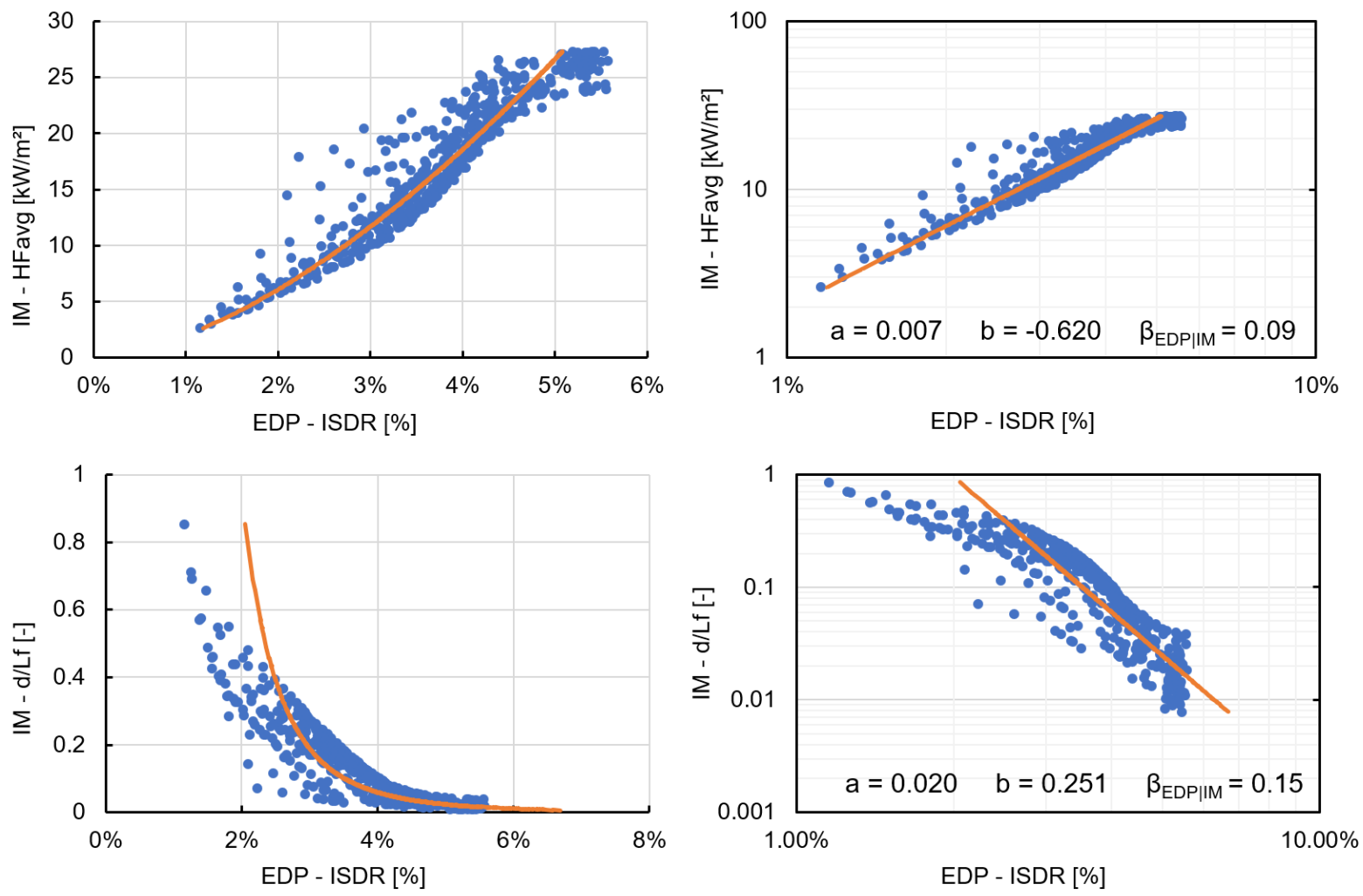

Figure 14 - Cloud analysis and linear regression for IMs: (a) D; (b) d; (c) q; (d) L/D; (e) Lf; (f) HFavg; (g) d/Lf 


\subsection{Efficiency and relative sufficiency of IMs}

An IM is qualified efficient if it generates low variations between actual and predicted EDP values for a given IM value. That variation is characterised by the dispersion $\beta_{\text {EDPIIM }}$ of the EDP conditioned on the IMs, which is satisfying when its value is low. Usually a value of lower than 0.3 is considered efficient [44]. As explained in Section 4.1.1, this value was straightforward to evaluate through CA with Eq. (21) once coefficients $a$ and $b$ were determined. For each of the 7 candidate IMs, the values of dispersion $\beta_{E D P \mid I M}$ were computed and reported in Figure 14. Based on these values the efficiency of the 7 IM candidates could be compared in Figure 15. Eventually, Figure 15 highlights that all IM candidates are efficient since they exhibit dispersion values lower than 0.3. In particular, the most efficient candidate IM is the maximum average heat flux imping the structure $\mathrm{HF}_{\text {avg. }}$.

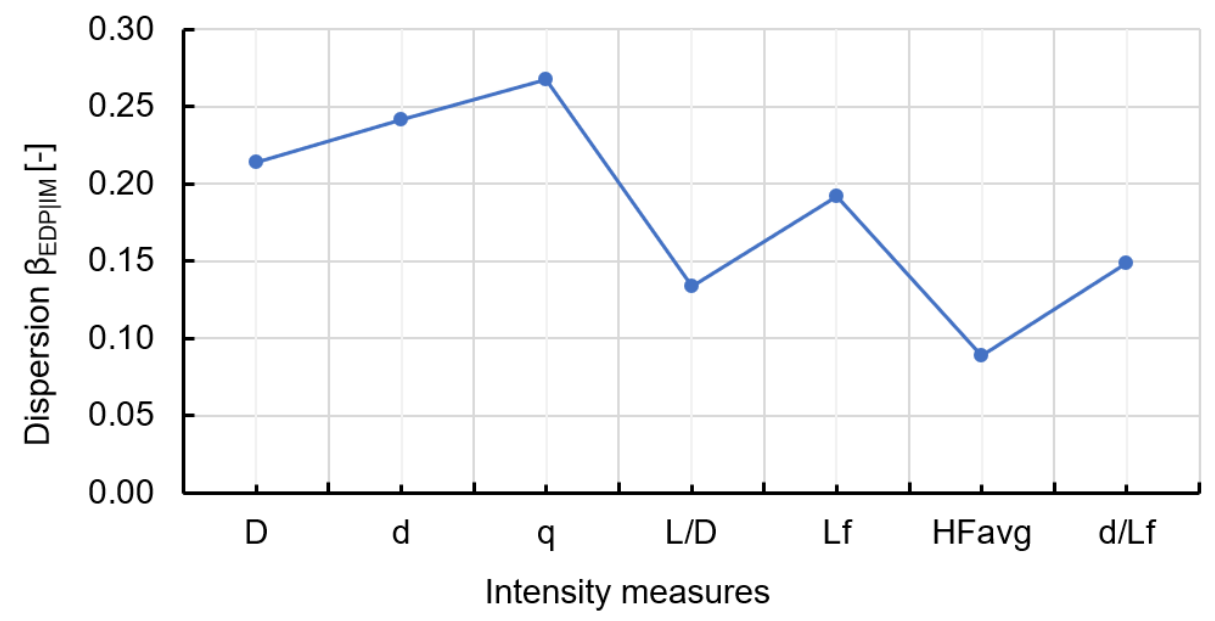

Figure 15 - Efficiency analysis results

In terms of sufficiency, Luco and Cornell [46] defined an IM as sufficient when the structural response (EDP) to a demand shows no trend in the correlation with the parameters defining this demand. For the IMs evaluated here, the sufficiency should be evaluated by verifying that the residuals of EDP shows no trend in the correlation with the basic fire parameters, i.e. D, $d$ and q. However, since all the IM candidates used in this work were defined as functions of these fire parameters to properly characterise the fire severity, a certain correlation was always observed between the residuals of EDP and the fire parameters. Hence, in order to provide a sufficiency measure, an alternative way to evaluate the sufficiency of IM candidates was employed by defining a relative sufficiency measure based on information theory concept [47]. This measure aims at evaluating the sufficiency of an IM comparatively with another one by considering the amount of information gained (on average) about the structural response. The relative sufficiency measure between $\mathrm{IM}_{1}$ and $I \mathrm{IM}_{2}$ is defined in Eq. (23) and is expressed in unit of bits of information.

$$
\mathrm{I}\left(\mathrm{EDP}\left|\mathrm{IM}_{2}\right| \mathrm{IM}_{1}\right) \approx \frac{1}{\mathrm{n}} \sum_{\mathrm{i}=1}^{\mathrm{n}} \log _{2} \frac{\mathrm{p}\left[\mathrm{EDP}=\mathrm{EDP}_{\mathrm{i}} \mid \mathrm{IM}_{2}\right]}{\mathrm{p}\left[\mathrm{EDP}=\mathrm{EDP}_{\mathrm{i}} \mid \mathrm{IM}_{1}\right]}
$$

$E_{D P}$ are the EDP values calculated for each of the $n$ fire scenarios $(n=539)$ and the probability distribution function (PDF) p[EDP|IM] is defined in Eq. (24), considering the dispersion defined in Eq. (21), and where $\phi\left({ }^{*}\right)$ is the standard Gaussian PDF. 


$$
\mathrm{p}\left[\mathrm{EDP}=\mathrm{EDP}_{\mathrm{i}} \mid \mathrm{IM}\right]=\frac{1}{\mathrm{EDP}_{\mathrm{i}} \cdot \beta_{\mathrm{EDP} \mid \mathrm{IM}}} \phi\left(\frac{\ln \left(\mathrm{EDP}_{\mathrm{i}} /\left(\mathrm{a} \mathrm{IM}_{\mathrm{i}}^{\mathrm{b}}\right)\right)}{\beta_{\mathrm{EDP} \mid \mathrm{IM}}}\right)
$$

$I M_{2}$ is more sufficient than $I M_{1}$ if $I M_{2}$ provides more information about the structural response (EDP) than $I M_{1}$, which is the case when I(EDP $\left.\left|I_{2}\right| I M_{1}\right)$ is positive. Symmetrically, IM $I_{2}$ is less sufficient than $I M_{1}$ when $\mathrm{I}\left(\mathrm{EDP}\left|\mathrm{IM} \mathrm{M}_{2}\right| \mathrm{IM} \mathrm{M}_{1}\right)$ is negative. For the $7 \mathrm{IM}$ candidates investigated here, sufficiency measures were evaluated relatively to fire diameter $D$ taken as the reference $I_{1}$. The relative sufficiency measures computed for the $7 \mathrm{IMs}$ were compared in Figure 16. This comparison highlights that the maximum average heat flux impinging the structure appears to be the most sufficient IM among the $7 \mathrm{IM}$ candidates considered herein. It has to be noted that relative sufficiency measures could have been evaluated considering another IM than $D$ as the reference $\mathrm{IM}_{1}$. However, the result would not change because the curve plotted in Figure 16 would be simply moving up or down.

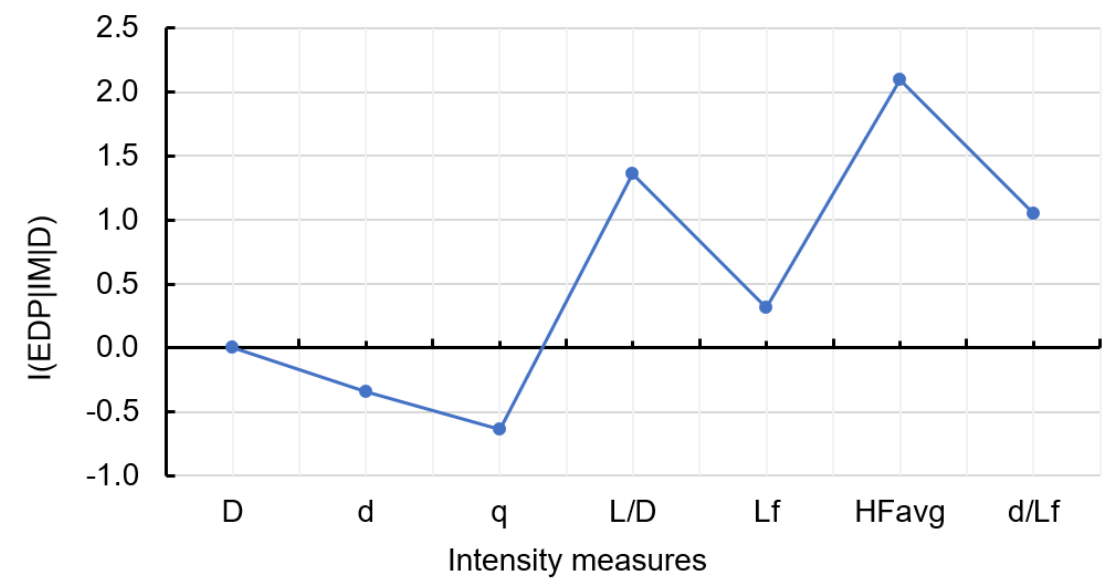

Figure 16 - Relative sufficiency analysis results of IMs with respect to $D$

\subsection{Fire fragility functions}

Based on the definition of the probabilistic fire demand models, fragility functions were derived considering the maximum average heat flux impinging the structure $\mathrm{HF}_{\text {avg }}$ as $\mathrm{IM}$, since it was found to be the most efficient and sufficient one. The ISDR was used as EDP and the two limit states (LS) defined in Section 4.3 were considered. Applying the CA, fragility functions could be derived for both LS using Eq. (22). As illustrated in Figure 14f, when $\mathrm{HF}_{\text {avg }}$ was taken as IM, coefficients a and $b$ were found to be equal to 0.007 and 0.620 , respectively, and they yielded the dispersion value $\beta_{\text {EDP IIM }}$ of 0.09 . Fragility curves are plotted in Figure 17 that show the probability of the interstorey drift ratio ISDR exceeding $5 \%$ and $2.5 \%$

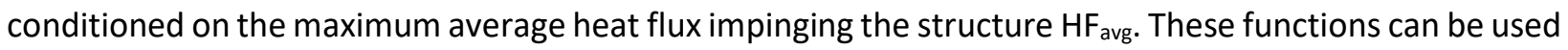
to quantify the probability that a steel pipe-rack exposed to localised fire exceeds a predefined LS. It is possible to note that when $\mathrm{HF}_{\text {avg }}>30 \mathrm{~kW} / \mathrm{m}^{2}$ the probability of exceeding an ISDR value of $5 \%$ becomes larger than $80 \%$, whereas it occurs for $\mathrm{HF}_{\text {avg }}>10 \mathrm{~kW} / \mathrm{m}^{2}$ when considering the life safety limit state, i.e. $\mathrm{ISDR}=2.5 \%$. Finally, fragility curves considering L/D as IM were also derived and plotted in Figure 18 , because it is an IM commonly used in practice. However, the given information does not depend on the fuel characteristics and it is not an IM as complete as $\mathrm{HF}_{\text {avg. }}$. Furthermore, the L/D IM was found to be the most efficient and sufficient after the maximum average heat flux impinging the structure $\mathrm{HF}_{\text {avg. }}$. The PFDM provided, through linear regression $a$ and $b$ coefficients to be equal to 0.026 and -0.976 and dispersion $\beta_{\text {EDP IIM }}$ equal to 0.13 , as illustrated in Figure $14 \mathrm{~d}$. It can be observed that these fragility curves are 
meaningful if $L / D \geq 0.5$, because when the $L / D$ decreases below 0.5 it means that part of the structure is engulfed into the localised fire and consequently a different structural response is expected with the ISDR no longer being the most appropriate EDP. Therefore, a grey shade for L/D values $<0.5$ was included in Figure 18 to highlight the validity range of the fire fragility curves. It may be observed that when L/D is larger than 0.75 the probability of exceeding an ISDR value of $5 \%$ becomes very low and only from L/D < 0.75 the probability increases. For $L / D=0.5$ it attains almost $60 \%$. When $L / D>1.5$ the probability of exceeding an ISDR $=2.5 \%$ becomes almost zero, whereas it overcomes $80 \%$ when $L / D<0.9$.

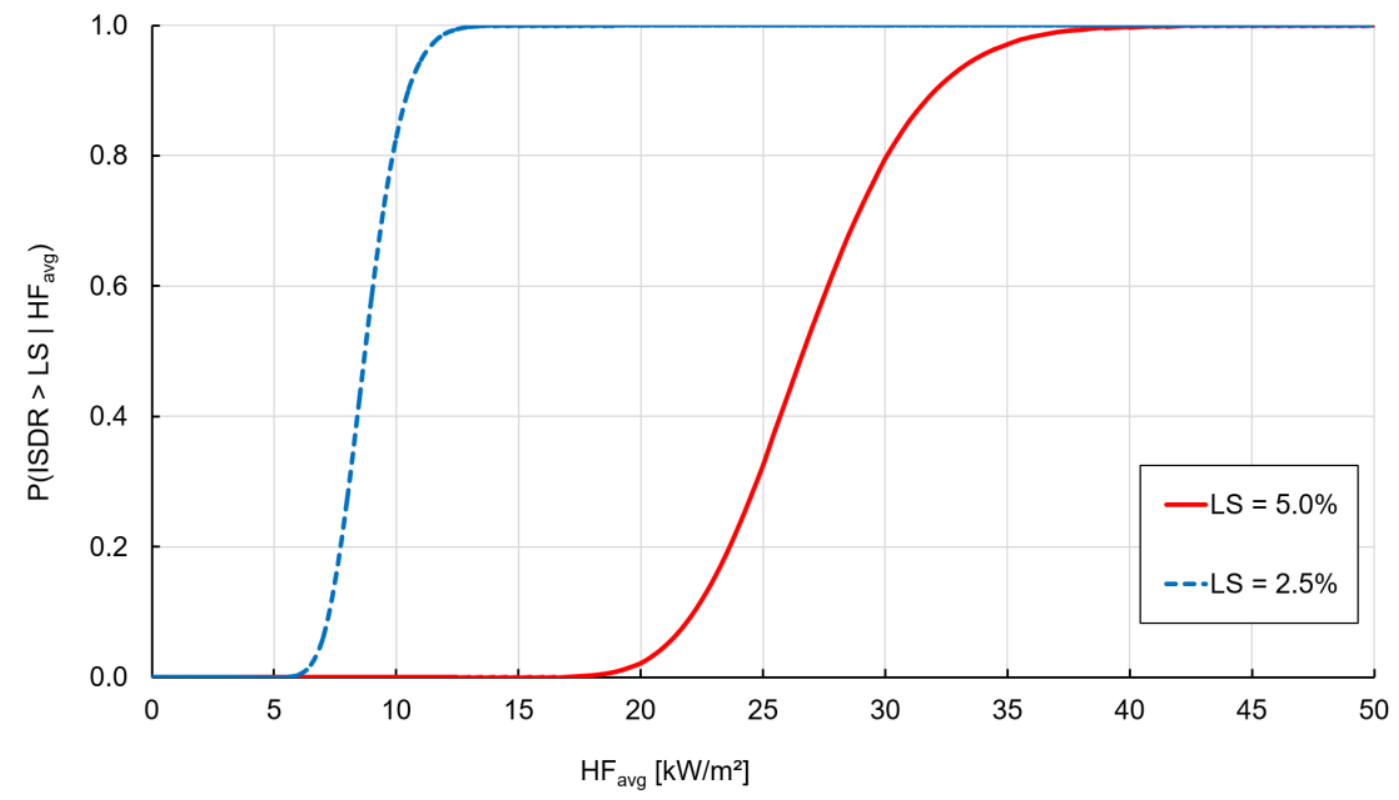

Figure 17 - Fragility curves based on CA for near collapse- and life safety preventions with HFavg as IM

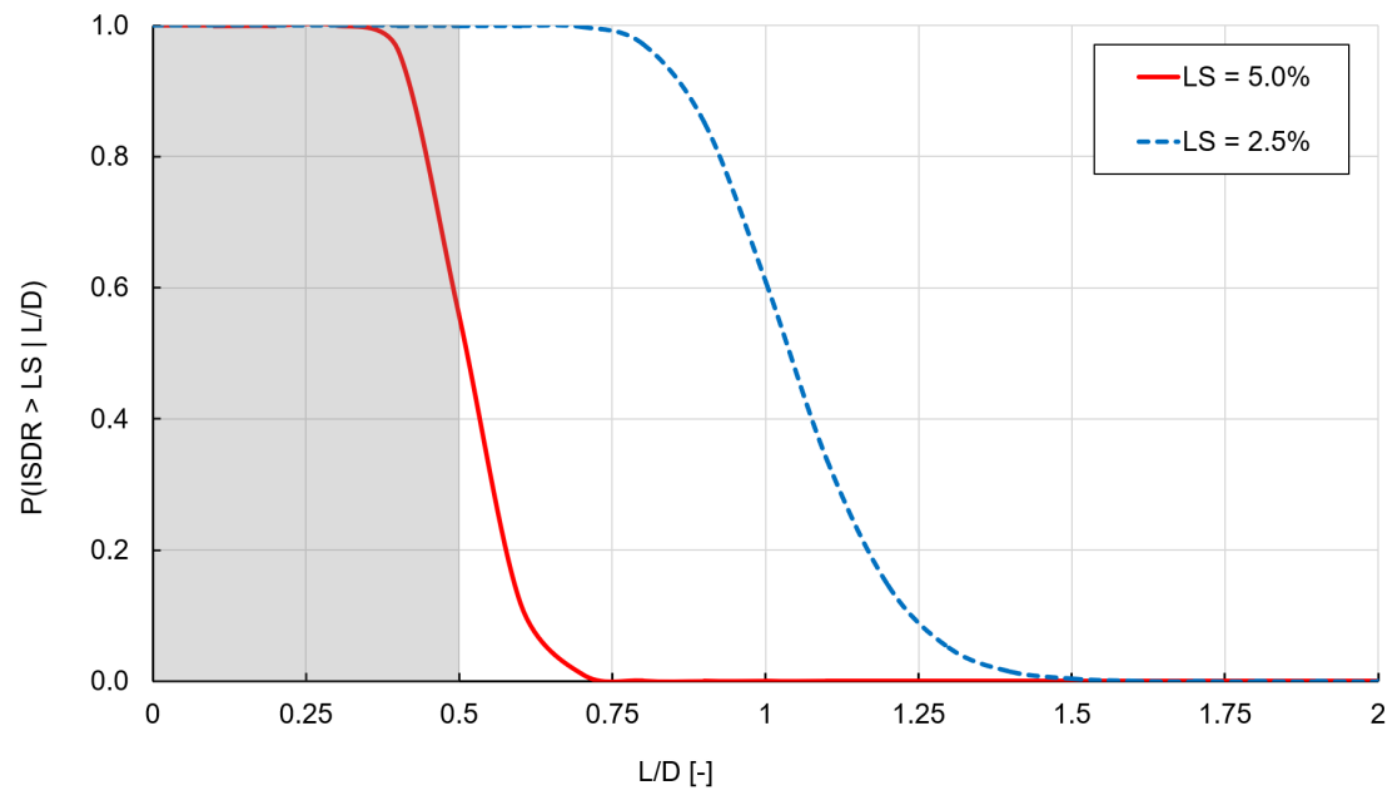

Figure 18 - Fragility curves based on CA for near collapse- and life safety preventions with L/D as IM 


\section{Conclusions}

This paper presented the development of a probabilistic fire demand model for a steel pipe-rack exposed to localised fires. Considering 539 localised plausible fire scenarios in industrial/petrochemical plants, thermo-mechanical analyses were performed with the FE software SAFIR that includes the LOCAFI localised fire model. Based on numerical analyses, probabilistic analyses were conducted to derive fire fragility functions by adopting the cloud analysis (CA) method. The maximum transversal interstorey drift ratio (ISDR) was found to be the most suitable EDP for this case study, because it provides a global measure of the structural response as it can be directly related to damage and collapse of a significant part of the pipe rack. In this respect, two structural ultimate limit states, near collapse and life safety, were defined for ISDR exceeding $5 \%$ and $2.5 \%$, respectively. Seven intensity measures (IM) were studied and compared based on their efficiency and relative sufficiency. The maximum average heat flux impinging the structure $\mathrm{HF}_{\text {avg }}$ and the ratio between fire position and fire diameter L/D appeared to be the most efficient IMs to characterise localised fire severity and also the most sufficient when relatively compared with other IMs. Thus, fire fragility functions were derived considering these two EDP-IM pairs, i.e. ISDR-HFavg and ISDR-L/D. Focusing on the near collapse limit state, fragility functions showed that localised fires generating $\mathrm{HF}_{\text {avg }}$ lower than $20 \mathrm{~kW} / \mathrm{m}^{2}$ have low probability of exceedance. Conversely, when $\mathrm{HF}_{\text {avg }}$ is higher than $35 \mathrm{~kW} / \mathrm{m}^{2}$, it is close to 1 . For L/D values higher than 0.75 the probability of exceedance an ISDR of $5 \%$ is very low. Regarding the life safety limit state, fragility functions showed for $\mathrm{HF}_{\text {avg }}$ higher than $15 \mathrm{~kW} / \mathrm{m}^{2}$ the probability of exceedance is very high, as well as when the L/D value varies between 0.5 and 0.75 . In sum, the CA can be considered an appropriate and versatile method to develop PFDMs from which building fire fragility functions to be used in fire risk assessment or in a fully probabilistic structural fire engineering (PSFE) framework of steel pipe-rack design. Future works will be addressed to consider multiple burning pool fires and the presence of the wind.

\section{Acknowledgments}

This research has been funded by the European XP-Resilience project through the grant agreement number 721816. Moreover, funding from the Italian Ministry of Education, University and Research (MIUR) in the frame of the Departments of Excellence Initiative 2018-2022 attributed to DICAM of the University of Trento is also acknowledged. 


\section{References}

[1] B. Zheng and G. Chen, "Storage Tank Fire Accidents," Process Saf. Prog., vol. 30, no. 3, 2011.

[2] V. Uehara, "Fire Safety Assessments In Petrochemical Plants," in Fire Safety Science - Third international symposium, 1991, pp. 83-96.

[3] J. I. Chang and C. Lin, "A study of storage tank accidents," J. Loss Prev. Process Ind., vol. 19, pp. 51-59, 2005.

[4] D. Pantousa, "Thin-Walled Structures Numerical study on thermal buckling of empty thin-walled steel tanks under multiple pool- fi re scenarios," Thin Walled Struct., vol. 131, no. January, pp. 577-594, 2018.

[5] C. Shu and C. Chong, "Applications of 3D QRA technique to the fire / explosion simulation and hazard mitigation within a naphtha-cracking plant," J. Loss Prev. Process Ind., vol. 22, no. 4, pp. 506-515, 2009.

[6] C. Bernier and J. E. Padgett, "Fragility and risk assessment of aboveground storage tanks subjected to concurrent surge, wave, and wind loads," Reliab. Eng. Syst. Saf., no. February, 2019.

[7] H. N. Phan, F. Paolacci, O. S. Bursi, and N. Tondini, "Seismic Fragility Analysis of Elevated Steel Storage Tanks Supported by Reinforced Concrete Columns," J. Loss Prev. Process Ind., vol. 47, no. February, pp. 57-65, 2017.

[8] F.Paolacci, O.Bursi, Md.S.Reza, A.Kumar, and A.M.Gresnigt, "Main Issues On The Seismic Design Of Industrial Piping Systems And Components," in ASME 2013 Pressure Vessels \& Piping Division Conference, 2013, pp. 1-10.

[9] F. Paolacci, "Structural safety of industrial steel tanks; pressure vessels and piping - Basic seismic structural design of a typical piping system," University of RomaTre, 2010.

[10] O. Bursi, F. Paolacci, M. S. Reza, S. Alessandri, and N. Tondini, "Seismic Assessment of Petrochemical Piping Systems Using a Performance-Based Approach," J. Press. Vessel Technol., 2010.

[11] F. Paolacci, O. S. Bursi, and R. Md.Shahin, "SEISMIC ANALYSIS AND COMPONENT DESIGN OF REFINERY," in Conference on Computational Methods in Structural Dynamics and Earthquake Engineering, 2011, no. May, pp. 26-28.

[12] O. S. Bursi, F. Paolacci, and M. S. Reza, "Performance-Based Analysis of Coupled Support Structures and Piping Systems," in ASME 2015 Pressure Vessels \& Piping Division Conference, 2015 , no. July.

[13] M. Nakashima, O. Lavan, M. Kurata, and Y. Luo, "Earthquake engineering research needs in light of lessons learned from the 2011 Tohoku earthquake," Earthq. Eng. Eng. Vib., vol. 13, pp. 141149, 2014.

[14] M. Campedel, "Analysis of Major Industrial Accidents Triggered by Natural Events Reported In the Principal Available Chemical Accident Databases," University of Bologna, European Commission Joint Research Centre Institute for the Protection and Security of the Citizen, 2008. 
[15] C. European Commitee for Standardization, "Eurocode 1: Actions on structures - Part 1-2: General actions - actions on structures exposed to fire. EN 1991-1-2." European Commitee for Standardization, CEN, Brussels, 2002.

[16] M. Shokri and C. L. Beyler, "Radiation from large pool fires," SFPE Handb. Fire Prot. Eng., vol. 4, no. 1, pp. 141-150, 1989.

[17] C. L. Beyler, "Fire Hazard Calculations for Large, Open Hydrocarbon Fires," SFPE Handbook of Fire Protection Engineering. Springer US, 2016.

[18] G. Heskestad, "Engineering relations for fire plumes," Fire Saf. J., vol. 7, no. 2, pp. 25-32, 1984.

[19] P. J. Rew and W. G. Hulbert, "Development of pool fire thermal radiation model," in HSE Contract Research Report, 1996.

[20] V. Babrauskas, "Estimating large pool fire burning rates," Fire Technol., pp. 251-261, 1983.

[21] P. H. Thomas, "The size of flames form natural fires," in Symposium International on Combustion, Vol 9, 1963, pp. 844-859.

[22] K. S. Mudan, "Thermal Radiation hazards from hydrocarbon pool fires," Prog. Energy Combust. Sci., vol. 10, pp. 59-80, 1984.

[23] D. Li-bin, P. Jin-yun, and R. Kai, "Analysis of thermal radiation models for large open pool fire on ship deck," Appl. Mech. Mater., vol. 470, pp. 259-262, 2014.

[24] E. Ufuah and C. G. Bailey, "Flame Radiation Characteristics of Open Hydrocarbon Pool Fires," in Proceedings of the World Congress on Engineering, 2011, vol. III.

[25] P. Francis, N. Baddo, F. Hanus, and C. Thauvoye, "Design of columns subject to localised fires," The Steel Construction Institute (SCI), 2018.

[26] N. Tondini, C. Thauvoye, F. Hanus, and O. Vassart, "Development of an analytical model to predict the radiative heat flux to a vertical element due to a localised fire," Fire Saf. J., vol. 105, no. March, pp. 227-243, 2019.

[27] D. Kamikawa, Y. Hasemi, T. Wakamatsu, and K. Kagiya, "Experimental flame heat transfer correlations for a steel column adjacent to and surrounded by a pool fire," in Fire Safety Journal, pp. 989-1000.

[28] A. Santiago, G. Ferraz, J. P. Rodrigues, and P. Barata, "Thermal analysis of hollow steel columns exposed to localised fires," Fire Technol., vol. 52, pp. 663-681, 2016.

[29] F. Hanus, O. Vassart, N. Tondini, A. Nadjai, and J. Franssen, "Temperature assessment of a vertical steel member subjected to localised fire: Experimental tests," in Proceedings of the 9th Conference on Structures in Fire, 2016.

[30] N. Tondini and J.-M. Franssen, "Analysis of experimental hydrocarbon localised fires with and without engulfed steel members," Fire Saf. J., vol. 92, no. May, pp. 9-22, 2017.

[31] D. T. Gottuk and D. A. White, "Liquid fuel fires," SFPE Handb. Fire Prot. Eng., no. 12, pp. 25522590, 2016.

[32] Committee for the prevention of disasters by hazardous materials, "Methods for the calculation of physical effects due to releases of hazardous materials - Yellow Book." Gevaarlijke Stoffen, The 
Hague, 2005.

[33] J. A. Vílchez, V. Espejo, and J. Casal, "Generic event trees and probabilities for the release of different types of hazardous materials," J. Loss Prev. Process Ind., vol. 24, no. 3, pp. 281-287, 2011.

[34] M. Moosemiller, "Development of algorithms for predicting ignition probabilities and explosion frequencies," J. Loss Prev. Process Ind., vol. 24, no. 3, pp. 259-265, 2011.

[35] T. Gernay, N. E. Khorasani, and M. Garlock, "Fire fragility curves for steel buildings in a community context : A methodology," Eng. Struct., vol. 113, pp. 259-276, 2016.

[36] T. Gernay, N. E. Khorasani, and M. Garlock, "Fire Fragility Functions for Steel Frame Buildings: Sensitivity Analysis and Reliability Framework," Fire Technol., vol. 55, no. 4, pp. 1175-1210, 2019.

[37] D. Lange, S. Devaney, and A. Usmani, "An application of the PEER performance based earthquake engineering framework to structures in fire," Eng. Struct., vol. 66, pp. 100-115, 2014.

[38] M. Shrivastava, A. K. Abu, R. P. Dhakal, and P. J. Moss, "Severity measures and stripe analysis for probabilistic structural fire engineering," Fire Technol., vol. 55, no. 4, pp. 1147-1173, 2019.

[39] C. A. Cornell and H. Krawinkler, "Progress and challenges in seismic performance assessment," Peer Cent. News, vol. 3, no. 2, pp. 1-3, 2000.

[40] K. R. Mackie and B. Stojadinovic, "Comparison of incremental dynamic, cloud, and stripe methods for computing probabilistic seismic demand models," in Structures Congress, 2005.

[41] N. Shome, C. A. Cornell, P. Bazzurro, and J. E. Carballo, "Earthquakes, Records, and Nonlinear Responses," Earthq. Spectra, vol. 14, pp. 469-500, 1998.

[42] C. A. Cornell, F. Jalayer, R. O. Hamburger, and D. A. Foutch, "Probabilistic Basis for 2000 SAC Federal Emergency Management Agency Steel Moment Frame Guidelines," J. Struct. Eng., no. April, pp. 526-533, 2002.

[43] K. R. Mackie and B. Stojadinovic, "Seismic demand for performance-based design of bridges," Pacific Earthquake Engineering Research Center - University of California Berkeley, 2003.

[44] N. Tondini and B. Stojadinovic, "Probabilistic seismic demand model for curved reinforced concrete bridges," Bull. Earthq. Eng., 2012.

[45] J. W. Baker, "Efficient analytical fragility function fitting using dynamic structural analysis," Earthq. Spectra, vol. 31, pp. 579-599, 2015.

[46] N. Luco and C. A. Cornell, "Structure-Specific Scalar Intensity Measures for Near-Source and Ordinary Earthquake Ground Motions," Earthq. Spectra, vol. 23, no. 2, pp. 357-392, 2007.

[47] H. Ebrahimian, F. Jalayer, A. Lucchini, F. Mollaioli, and G. Manfredi, "Preliminary ranking of alternative scalar and vector intensity measures of ground shaking," Bull. Earthq. Eng., pp. 28052840, 2015.

[48] "XP-RESILIENCE: Extreme loading analysis of petrolchemicals plants and design of metamaterialbased shields for enhanced resilience," 2015. [Online]. Available: https://r.unitn.it/en/dicam/xpresilience.

[49] J.-M. Franssen and T. Gernay, "SAFIR: a thermal/structural program for modeling structures 
under fire." University of Liège, Liège.

[50] European Committee for Standardization CEN, "Eurocode 3: Design of steel structures - Part 1-2: General rules - structural fire design. EN 1993-1-2." European Commitee for Standardization, CEN, Brussels, 2005.

[51] D. Drysdale, An Introduction to Fire Dynamics, Third edit. John Wiley \& Sons, 2011.

[52] M. G. Zabetakis and D. S. Burgess, "Research on the Hazards Associated with the Production and Handling of Liquid Hydrogen," Ohio, USA, 1960.

[53] D. Vamvatsikos and C. A. Cornell, "Incremental dynamic analysis," Earthq. Eng. Struct. Dyn., vol. 31, no. August 2001, pp. 491-514, 2002.

[54] FEMA and ASCE, "FEMA 356 - Prestandard and commentary for the seismic rehabilitation of buildings," no. November. Federal Emergency Management Agency, 2000. 